Revista lus et Praxis, Año 16, № 1, 2010, pp. 125 - 170

ISSN 0717 - 2877

Universidad de Talca - Facultad de Ciencias Jurídicas y Sociales

"Declaración de la parte como medio de prueba"

Felipe Marín Verdugo

\title{
DECLARACIÓN DE LA PARTE COMO MEDIO DE PRUEBA*
}

\author{
PARTY AS WITNESS
}

Felipe Marín Verdugo**

\begin{abstract}
RESUMEN
Los procedimientos judiciales chilenos han sufrido importantes cambios en las últimas dos décadas. Han transitado desde un sistema escrito a uno por audiencias. Esto ha significado un nuevo diseño de la audiencia de juicio y, en particular, de las reglas de la prueba. El alcance de estos cambios no es aun totalmente comprendido, lo que permite la sobrevivencia de algunas prácticas del sistema escrito anterior dentro del nuevo. Este trabajo identifica una de ellas, que consiste en la exclusión de las partes como testigos en sus propios juicios. Se explicará cuál fue el fundamento de esta exclusión en el sistema escrito anterior y cómo éste ha sido superado en varios ordenamientos comparados. Se sostendrá que en el contexto de los nuevos sistemas por audiencias chilenos, en los que el juez debe valorar la prueba en concreto, dicha exclusión carece de sentido y las partes deben ser admitidas para declarar voluntariamente. Se sostendrá también que las nuevas reglas de la prueba lo permiten, analizándolas pormenorizadamente. Asimismo se contestará a los argumentos esgrimidos para justificar la mantención de esta exclusión y, finalmente, se propondrá una manera de rendir la declaración de la parte como testigo en conformidad a las nuevas reglas de la prueba.
\end{abstract}

ABSTRACT

During the last two decades, the Chilean judicial procedures have undergone an important reform process. It went from a written procedure to a hearing-based procedure. This change involved a new design for the trial hearing and, in particular, for the rules of evidence. The meaning of these changes is not yet well understood, making it easier for the survival of former practices of the written system within the new hearing-based system. This paper identifies on of them, which is the exclusion of parties as witnesses. The paper explains the reasons of the origin of this rule of exclusion in the former written procedure and how it was subsequently overcome in several comparative systems. The paper will hold that in the context of the new hearing-based system, where the judge must concretely assess the evidence, this kind of exclusion lacks of sense, therefore the parties must be admitted into evidence. Moreover, the paper will show that the new rules of evidence allow parties to give their testimony by analyzing those rules in detail. The paper will also refute the

\footnotetext{
*Trabajo recibido el 10 de marzo y aprobado el 21 de abril de 2010.

** Abogado; Master of Legal Institutions de la Universidad de Wisconsin; Profesor Asistente de la Facultad de Derecho Universidad Diego Portales. Correo electrónico: felipe.marin@udp.c.
} 
supporting arguments used to defend the maintenance of this exclusion in the new hearing-based system and, at last, it will suggest a way to perform the party's testimony accordingly to the new rules of evidence.

PaLABRAS CLAVE

Reforma Procesal, Declaración de Parte como Medio de Prueba, Reglas de la Prueba

KEY WORDS

Procedural Reform, Party as Witness, Rules of Evidence

\section{INTRODUCCIÓN}

Desde la década de los noventa del siglo pasado Chile ha transitado por un camino de profundos cambios en sus diversos sistemas judiciales. Primero fue la reforma Procesal Penal, luego el nuevo procedimiento de Familia y finalmente la reforma al procedimiento Laboral.' El proceso no se detendrá en el futuro: hay una comisión convocada por el Ministerio de Justicia trabajando en la elaboración de un nuevo sistema de justicia comunitaria, se ha anunciado un proyecto de reforma al procedimiento de Justicia Militar y, probablemente el más importante, ha sido presentado al Congreso en 2009 un proyecto para reformar el Código de Procedimiento Civil.

A pesar de las diferencias en el derecho sustantivo de cada una de estas reformas procesales, todas las que ya están en marcha y las proyectadas tienen un denominador común: se trata de sistemas procesales por audiencias. Esto significa que, en lo medular, las decisiones judiciales deben ser tomadas personalmente por el juez, previa audiencia dirigida por él mismo, en la que ha presenciado directamente el debate de los litigantes (sus argumentos y prueba). A estos procedimientos por audiencias se los ha denominado genéricamente como sistemas "orales" o procedimientos en los que prima el principio de la "inmediación".

La diferencia con el sistema anterior es radical. En éste, el juez no obtenía la información para tomar sus decisiones de lo que hubiese escuchado decir directamente en una audiencia a los abogados, las partes y demás medios de prueba, sino que obtenía la información que necesitaba de la lectura del expediente, que era un registro escrito de lo que habían dicho los abogados, las partes y demás medios de prueba en algún otro momento del proceso judicial. Además, por regla general, el juez no intervenía directamente en el proceso de formación del expediente, sino que delegaba esta labor en funcionarios subal-

\footnotetext{
${ }^{1}$ También fue modificado el procedimiento tributario, pero no se menciona como una de las reformas ya que su única modificación relevante consistió en crear un juez tributario independiente de la administración, pero mantuvo un procedimiento escrito y con delegación de funciones, lo que se aparta de los avances -más o menos exitosos- que tienen en común las demás modificaciones procesales mencionadas.
} 
ternos de su tribunal. De esta manera, por ejemplo, la declaración de un testigo era recibida por un funcionario del juez (un actuario), quien levantaba un acta de lo declarado por éste y la adjuntaba al expediente. Posteriormente el juez leería ésta y las demás declaraciones adjuntadas al expediente para informarse y dictar sentencia. Por esto es que este sistema procesal era caracterizado como "escrito" y "mediato".

Como parece evidente, uno de los principales avances ofrecido por el sistema por audiencias consiste en mejorar la calidad de la información con la que cuenta el juez para formar su juicio sobre los hechos debatidos. Ahora estará en contacto directo con las fuentes que contienen la información necesaria para resolver el asunto controvertido, aumentando con ello la posibilidad de llegar a una decisión correcta o, al menos, disminuyendo la posibilidad de cometer errores.

Por ello, uno de los cambios más trascendentales del nuevo sistema por audiencias está en el diseño de la audiencia de juicio, aquella destinada a recibir la información que utilizará el juez para resolver el fondo del asunto. A su vez, dentro de la audiencia de juicio, el cambio más importante está en las normas que regulan la manera en que se debe producir y valorar la prueba (las reglas de la prueba), pues ellas son las que definen la manera en que la información podrá ser introducida, usada y valorada en el juicio².

De acuerdo a las nuevas reglas de la prueba, como se ha dicho, el juez ahora debe acceder directamente, sin intermediarios, a las fuentes de información con las que construirá su decisión. Por lo tanto, el juez verá y escuchará personalmente la declaración de los testigos en lugar de leer un acta redactada por un funcionario del tribunal, quien la tomó y resumió tiempo antes, como ocurría en el sistema escrito. Junto a ello, las reglas de la prueba entregan a las partes y al tribunal herramientas más eficientes y menos formalistas para examinar la calidad de la información que entregan las personas que declaran en la audiencia a través de preguntas o demostraciones que manifiesten su buena o mala calidad. Además, la prueba percibida directamente por el juez debe ser recibida en un solo acto con el objeto de facilitar su valoración inmediata.

Una vez que la información se ha producido de esta manera, las nuevas reglas de la prueba facultan a los jueces para valorarla de acuerdo a las reglas de la sana crítica. Esto significa que los jueces tienen libertad para valorar los medios de prueba, pero teniendo como límite no contradecir los principios de

\footnotetext{
${ }^{2}$ La importancia de la prueba en la conformación de un procedimiento civil es clarísima: "En cierto sentido, el núcleo del proceso civil es la asunción de las pruebas. En realidad, describir un proceso de primera instancia equivale, en buena medida, a dar cuenta de cómo se ofrecen, solicitan, admiten y asumen las pruebas". TARuffo, Michele, La prueba, Traducción de Manríquez, Laura; Ferrer, Jordi, Editorial Marcial Pons, Madrid, España, 2008, p. 109.
} 
la lógica, las máximas de la experiencia y los conocimientos científicamente afianzados ${ }^{3}$.

Pero valorar de acuerdo a las reglas de la sana crítica también significa que los jueces deben apreciar la prueba de manera concreta, es decir, deben darle más o menos valor (credibilidad) de acuerdo a su propio peso, sólo después de haber conocido su contenido específico individual y en conjunto con todas las demás pruebas que se rindieron en el juicio. Hoy este método puede parecer del todo natural. ¿Cómo se podría haber valorado seriamente la credibilidad de algo o alguien sin primero haberlo conocido y haber escuchado lo que tenía que decir? ¿Cómo se podría haber valorado la credibilidad de un testigo sin primero haberlo visto enfrentar, con o sin éxito, las contradicciones a las que haya podido ser expuesto?

Sin embargo, el sistema de valoración de la prueba fue otro durante siglos. La prueba era valorada antes de ser rendida en el juicio, por categorías generales, aisladamente una de otra y la persona a cargo de hacerlo no era el juez, sino que el legislador. A diferencia del sistema de valoración en concreto, éste era entonces un sistema de valoración a priori y en abstracto, conocido como el sistema de prueba legal o prueba tasada, nacido en Europa en la edad media, asociado históricamente a los sistemas en los que primó la escrituración y que existió en nuestros sistemas procesales desde la colonia para luego trasladarse hacia nuestros códigos republicanos.

El desafío de cambiar desde un sistema eminentemente escrito hacia uno por audiencias no es fácil, especialmente cuando el primero rigió por tantos años, echando profundas raíces en nuestra cultura legal. Por ello resulta comprensible que, a pesar de las reformas legales, aun persistan en los nuevos tribunales ciertas prácticas incompatibles con el nuevo sistema, las que incluso pueden llegar a no ser necesariamente percibidas como inconsistentes por algunos jueces y abogados. Sin embargo, es imprescindible que estas prácticas disfuncionales cambien hacia otras que sean coherentes con un sistema por audiencias si se pretende aprovechar sus ventajas.

En este trabajo se tratará una de estas prácticas disfuncionales. Ella se relaciona con la aplicación de algunas de las nuevas reglas de la prueba, el área, como se ha dicho, en que el sistema por audiencias está llamado a cumplir sus objetivos más trascendentales. ${ }^{4}$ Esta práctica consiste en que hoy, en el nuevo

\footnotetext{
${ }^{3}$ Ver artículo 456 del Código del Trabajo, artículo 32 de la Ley № 19.968 de Tribunales de Familia y artículo 297 del Código Procesal Penal. Para más detalle sobre el significado de "sana crítica" ver González Castillo, Joel, "La fundamentación de las sentencias y la sana crítica", Revista Chilena de Derecho No 1 vol. 33, 2006; Couture, Eduardo, Fundamentos del Derecho Procesal Civil, $4^{a}$ edición, Editorial B de F, Montevideo, Uruguay, 2007, pp. 222 y ss.

${ }^{4}$ Como señala Mauro Cappelletti, "La oralidad se refiere (...) principalmente a los hechos: a su alegación y a su prueba". Ver Cappelletti, Mauro, El testimonio de la parte en el sistema de la oralidad, Parte Primera, Traducción de Banzhaf, Tomás A., Librería Editora Platense, La Plata, 2002, p. 42.
} 
procedimiento de Familia y Laboral, los únicos procedimientos no-penales reformados vigentes hasta ahora en Chile, muchos de nuestros tribunales no permiten que las personas directamente involucradas en el conflicto, es decir, las partes, puedan tomar voluntariamente el estrado, entregar al juez la información de la que disponen y que lo que hayan dicho sirva como medio de prueba para formar la convicción en concreto del tribunal sobre los hechos debatidos, a pesar de ser, por regla general, quienes más conocimiento tienen de ellos. ${ }^{5} \mathrm{Si}$ permiten, en cambio, que la parte contraria obligue a declarar a la otra a través de su confesión forzada. ${ }^{6}$

¿Qué sentido tiene impedir a las partes declarar voluntariamente? ¿Cómo se le explica a un trabajador que ha acudido a los nuevos juzgados del trabajo que no puede exponer directamente al tribunal, con valor probatorio, lo que vio o escuchó, a menos que el empleador se lo permita al pedir su declaración forzada? ¿Cómo se le explica a una mujer que acude a un juzgado de familia pidiendo su divorcio por haber sido víctima de maltratos psicológicos graves, que no puede contar su historia al tribunal, con valor probatorio, salvo que el marido le allane el camino pidiendo su confesión? ¿Cómo se convence a un tribunal sobre lo señalado por alguna de las partes en aquellos aspectos de su demanda donde la mejor prueba disponible es lo percibido directamente por ella misma, ya sea por la dinámica propia de los hechos o por la dificultad para obtener testimonios de terceros renuentes a declarar? ¿Es inteligente poner a las partes en la situación de tener que elegir entre arriesgar perder el juicio por falta de prueba o "inventar" prueba para llenar el vacío dejado por la imposibilidad de decirlo directamente? ¿ ¿Es valioso que el tribunal se prive de la posibilidad de conocer información pertinente de boca de los propios protagonistas del conflicto?

En este trabajo se sostendrá que esta práctica de inhabilitar o excluir a las partes para declarar voluntariamente como testigos en sus propios juicios es propia de los sistemas escritos, donde esta práctica sí tenía coherencia y sustento legal, pero que su mantención en los nuevos sistemas por audiencias es incoherente con sus fundamentos y, más aún, carece de todo sustento legal. Se sostendrá, más aun, que las nuevas reglas de la prueba disponen exactamente

\footnotetext{
${ }^{5}$ El análisis estará centrado en los procedimientos de Familia y Laboral ya que, dentro de los sistemas reformados en funcionamiento, éstos son los únicos que presentan este problema. En el procedimiento penal, que es también un sistema por audiencias, la práctica asentada es que tanto el acusado como la víctima pueden declarar. Todo lo dicho es aplicable, sin embargo, al proyecto de nuevo Código Procesal Civil presentado al Congreso Nacional para su discusión en 2009 pues adolece de los mismos problemas normativos que facilitan la mantención de la práctica que se trata en este trabajo.

${ }^{6}$ La constatación de la existencia de esta práctica ha sido realizada por el autor al participar en diversos cursos con jueces de familia y laborales, de la experiencia compartida con abogados practicantes en estas áreas y del acceso a resoluciones judiciales de estos tribunales que han resuelto en ese sentido.
} 
lo contrario: las partes tienen la facultad legal de presentarse voluntariamente como testigos en sus propios juicios.

Para sustentar esta afirmación, el trabajo primero comenzará describiendo y analizando el sistema de prueba anterior a las reformas, el sistema de la prueba legal, donde se explicará porqué -por razones políticas, prácticas y culturales- se diseñó un sistema en el que el juez debía aplicar una valoración preestablecida por el legislador, es decir, una valoración a priori y en abstracto de la prueba. Se explicará también porqué la adopción de este sistema de prueba trajo como consecuencia la inhabilitación de las partes para declarar voluntariamente como testigos y que sólo pudieran hacerlo cuando la contraparte lo exigiera, permitiéndole al juez valorar sólo lo que ella hubiera dicho en contra de sus propios intereses. Se mostrará que esta manera de proceder encuentra su sustento en una forma de razonar propia de la época en que surgió el sistema de prueba legal, el medioevo, y que fue denominado como pensamiento escolástico.

Una vez explicado lo anterior, se hará un breve repaso de la superación del pensamiento escolástico y, junto con él, de la superación del mismo sistema de prueba legal, que incluía la inhabilidad de las partes para declarar voluntariamente como testigos. Esto llevó a un sistema de valoración de la prueba diferente, el de la valoración judicial o valoración en concreto. Junto con ello se mostrará como, en los ordenamientos más importantes de nuestra órbita cultural, este cambio en la forma de pensar se tradujo en modificaciones a las reglas de la prueba, incorporando la valoración en concreto y, por ende, la declaración voluntaria en beneficio de la parte como un medio de prueba valorable por el juez en su favor.

Luego se mostrará cómo las normas de nuestros procedimientos de Familia y Laboral han seguido esta evolución y no contienen ninguna prohibición para que las partes declaren voluntariamente como testigos, estableciendo reglas de la prueba que, por el contrario, la permiten. Se demostrará que las nuevas reglas establecen un sistema de valoración en concreto (sana crítica), lo que conduce a concluir que cualquier persona que haya percibido hechos pertinentes por sus sentidos, sean partes o terceros, sean o no interesados en el resultado del juicio, pueden declarar en él. El valor probatorio que se les asigne a sus declaraciones dependerá por completo de lo que ocurra en la audiencia de juicio, en concreto, sin prejuicios. Consistente con ello, se mostrará que las nuevas reglas de la prueba establecen un sistema abierto de medios de prueba (se puede probar un hecho a través de cualquier medio, mientras sea pertinente), a diferencia de lo que ocurría en el sistema escrito y, además, que existe un catálogo cerrado de razones por las cuales el juez puede excluir un medio de prueba, entre las cuáles no se encuentra ninguna que justifique la exclusión voluntaria de la parte sólo por el hecho de ser parte. 
Con esta información se contestará a continuación a algunos de los argumentos que se han usado para justificar la negativa a recibir el testimonio voluntario de las partes. Por último, se presentará una propuesta para producir la declaración voluntaria de las partes en el juicio según las normas existentes ya que éstas no la regulan explícitamente.

Por ahora, el trabajo intentará probar que las partes pueden declarar voluntariamente como testigos en el juicio sólo desde el punto de vista de la valoración judicial o valoración en concreto de la prueba. Sin embargo, es necesario hacer presente que existe otro punto de vista desde el cual también puede llegarse a la misma conclusión: el derecho subjetivo de las partes a ser oídas y su derecho a la defensa, reconocidos en los Tratados Internacionales como elementos integrantes del Debido Proceso. Lo anterior, por su propia complejidad y extensión, quedará para un trabajo independiente.

\section{El SISTEMA DE LA PRUEBA LEGAL}

Durante parte de la edad media el sistema judicial que cobró fuerza en el continente europeo fue el sistema romano-canónico, diseñado originalmente por la iglesia católica y que tenía sus raíces en el sistema romano del último periodo imperial.? Este procedimiento se caracterizó, entre otros, por buscar la verdad de los hechos, a diferencia de lo que ocurría con el sistema más primitivo de las ordalías o Juicio de Dios, que subsistió paralelamente, en el que más bien se intentaba buscar la solución de las disputas en la voluntad divina a través de pruebas mágicas o de destreza física. El abandono paulatino de esta forma de resolver los conflictos trasladándose hacia la búsqueda de la verdad constituyó un notable avance de racionalidad para su época, pero planteó un desafío sumamente difícil: la reconstrucción de hechos ocurridos en el pasado. Esto, a su vez, llevó necesariamente a recurrir a lo que conocemos hoy como "medios de prueba", es decir, a elementos informativos que entregaran testimonio al juez sobre hechos ocurridos en un momento remoto (pasado), de los cuales el juez no formó parte y, por ello, no presenció directamente. Sólo a través de estos medios de prueba el juez estaría en condiciones de reconstruir la "verdad" en el proceso judicial y, como consecuencia de ello, de aplicar el derecho a esos hechos tenidos por verdaderos. Esta mecánica sigue siendo así hasta el día de hoy y seguirá siendo necesaria mientras los conflictos que deba

\footnotetext{
${ }^{7}$ No todo el sistema de justicia romano tuvo las características del posterior sistema escrito, ya que durante el Imperio hubo sistemas en los que prevalecía la oralidad y libre valoración de la prueba. Sobre esto, ver López González, Jorge A., Teoría General sobre el Principio de Oralidad en el Proceso Civil, Editorial Juricentro, San José, Costa Rica, 2007, especialmente pp. 21 y ss.; y CAPpellettı, Mauro, El testimonio, cit. nota. n. 4.
} 
resolver un tribunal tengan su fuente en hechos pasados y no exista otra forma más confiable para acceder a ellos ${ }^{8}$.

Sin embargo, la importancia de la "verdad" en este sistema no debe ser sobredimensionada. Cuando encontrarla es un objetivo central del juicio, entonces debe ponerse especial énfasis en la calidad de la información entregada por los medios de prueba. Por lo mismo, debe cuidarse que las reglas de la prueba, aquellas encargadas de regular la forma de extraer e incorporar al juicio la información aportada por los medios de prueba, facilite alcanzar ese objetivo. Pero esto no ocurría así en este sistema, como se verá, pues hubo otros valores que competieron con mucha fuerza junto al interés por encontrar la verdad ${ }^{9}$, superándolo en la práctica, lo que terminó provocando la "desvalorización de la importancia del juicio sobre los hechos" y la "recíproca sobrevaloración del abstracto problema jurídico"10, característica que sigue presente hasta hoy en nuestra cultura legal influida durante tantos años por este modelo y que es problemática porque "ninguna decisión correcta y justa se puede basar en hechos determinados erróneamente" ${ }^{\prime 11}$.

\section{a) La escrituración y el control jerárquico}

Este sistema de justicia también se caracterizó por su escrituración, lo que, como se verá, tuvo una relevancia trascendental en el diseño de las normas que regularon la forma en que se debían rendir y valorar los medios de prueba.

La escrituración del proceso tuvo una importancia significativa y su existencia respondió a diversos factores. Uno de los más importantes fue de carácter político: el control jerárquico ejercido por el monarca. Ya fuera el Papa o el rey feudal, todos intentaban mantener el control de su precario poder en una época de alta inestabilidad política. Para ello, los distintos monarcas concentraban todos los poderes que hoy encontramos distribuidos en diferentes órganos de los estados republicanos: ejecutivo, legislativo y judicial. Sin embargo, por mucho que se estimara conveniente mantener centralizado el poder, su ejercicio concreto y cotidiano no podía materialmente ser realizado por una sola persona. Por lo mismo, cada monarca delegaba su ejecución en las personas (funcionarios) de su confianza, quienes no actuaban por sí mismos, sino que en su nombre.

\footnotetext{
${ }^{8}$ Sobre la importancia institucional de la "verdad" en los procedimientos judiciales, ver FerRer BeltrÁn, Jordi, La valoración racional de la prueba, Marcial Pons, Madrid, 2007, pp. 29 y ss.

${ }^{9}$ Esto no significa que en los sistemas procesales modernos no haya otros objetivos que compitan con el de encontrar la "verdad", como ocurre con la exclusión de prueba obtenida ilícitamente y el derecho de algunas personas a no contestar preguntas (secreto profesional, relaciones de parentesco), entre otras.

${ }^{10}$ Cappelletti, El Testimonio, cit. nota n. 4, p. 149.

${ }^{11}$ Taruffo, La Prueba, cit. nota n. 2, p. 23.
} 
El poder de impartir justicia era uno de los poderes que era necesario delegar. Entonces, respecto de los funcionarios a quienes se delegaba la función que hoy Ilamamos jurisdiccional, era necesario ejercer un control estricto para asegurar al monarca que ellos la ejercieran de acuerdo a su criterio, manteniendo con ello el poder concentrado.

La escrituración, en este contexto, fue un medio para permitir y facilitar el control. Si una de las partes se quejaba de la decisión de uno de los funcionarios delegados del rey o si el mismo monarca por propia iniciativa deseaba controlar lo que ellos estaban haciendo -aunque nadie apelara por su intervención- no necesitaba más que pedir al delegado que le devolviera el registro escrito (expediente) de todo lo actuado para revisar su corrección. Así, a través de su lectura, el monarca podía decidir ratificar lo realizado por su delegado o modificarlo en lo que estimara necesario de acuerdo a su propio criterio y convicción. La escrituración facilitaba enormemente las cosas, ya que de no existir el expediente escrito, la única forma del monarca para mantener el poder de decidir como única autoridad hubiese significado el penoso trabajo de hacer todo de nuevo -incluyendo volver a escuchar a los testigos- para formarse su propia idea de lo que había ocurrido y tomar su decisión final sobre el asunto.

Obviamente, para que este sistema de control funcionara correctamente se hacía imprescindible obligar a estos jueces/delegados a realizar un registro lo más completo y fiel posible. Producto de esta necesidad, en el sistema escrito se reglamentaba detalladamente cada paso para la formación del expediente y la forma de reconstruirlo en caso de pérdida, entre otras reglas que hacían manifiesta su importancia. Así, por ejemplo, la decretal del año 1216 de Inocencio III ordenaba que todos los actos procesales, inclusos aquellos ocurridos en presencia del juez, debían redactarse en actas y si el juez tomaba una decisión sobre la base de una información no escriturada y acompañada al acta, esa decisión era radical e insanablemente nula ${ }^{12}$. Y entonces el registro de lo que había ocurrido durante el proceso terminó por transformarse en el proceso mismo: el expediente era el juicio. Así se encargaba de dejarlo claro el aforismo que decía "quod non est in actis non est de hoc mundo" (si no está en el expediente, no está en el mundo).

\section{b) La escrituración y las reglas de la prueba}

En relación a los medios de prueba, la escrituración obligaba a transformar todo elemento informativo que diera luz sobre la verdad de los hechos, como la declaración de los testigos, en una pieza escrita que pudiera incorporarse al proceso, lo que materialmente se traducía en la agregación física de dicha pieza escrita al expediente. Si algún elemento informativo no había sido traducido al papel y agregado al expediente, entonces no era parte de proceso, no existía,

${ }^{12}$ Ver Cappelletti, El Testimonio, cit. nota n. 4, p. 143. 
porque el expediente era el proceso mismo. De esta manera, la prueba no era la declaración viva del testigo, sino que la "traducción" o "interpretación" de su declaración viva a través de la escrituración que quedaba registrada en un acta.

Esta "traducción", además, generalmente no era realizada directamente por el juez/delegado del monarca, sino que por un funcionario del juez/delegado al cuál éste le delegaba a su vez dicha función, lo que constituyó otra importante característica del sistema escrito. Jeremías Bentham lo describía así hace casi dos siglos: "la función de examinar a los testigos, de reunir las pruebas, a menudo se confía a un simple comisario, a un juez informador, quien transmite por escrito las actuaciones al juez superior, el cual falla de acuerdo al examen de los autos"13 y agregaba con tono crítico que "Esta forma de proceder subsiste todavía en varios países e incluso en Inglaterra, en el tribunal eclesiástico y en los tribunales de almirantazgo"14.

Por supuesto, es fácil advertir todos los problemas que esta "traducción" podía tener al momento de intentar valorar la prueba "traducida", ya que el juez/ delegado recibía esta información desnaturalizada a través de un funcionario que, incluso en el mejor de los escenarios, se limitaba sólo a modificar lo declarado por el testigo al resumirlo, pero que generalmente iba más allá al cambiar sus palabras, sin poder saber ni controlar hasta qué punto la declaración podía sufrir cambios sustantivos. Pero, además, al no haber visto nunca declarar al testigo, el juez/delegado perdía todo conocimiento de los elementos informativos que el testigo podía entregar por medios distintos a la palabra (gestos de duda, nerviosismo, demoras en contestar o, por el contrario, respuestas rápidas, seguras y claras), elementos usados cotidianamente para valorar la credibilidad de una persona.

Era este expediente, construido por un tercero delegado, el que recibía el juez/delegado para tomar su decisión final. Su juicio sobre los hechos, entonces, lo formaba a partir de los medios de prueba contenidos en el expediente, medios de prueba totalmente mediatizados, con los cuáles difícilmente podría haber realizado un ejercicio concreto de valoración. ¿Cómo saber si creerle más al testigo " $\mathrm{A}$ " que al testigo " $\mathrm{B}$ ", si el juez no sabe qué dijo exactamente cada uno y en qué condiciones? A falta de elementos informativos percibidos directamente por el juez, un ejercicio concreto de valoración de la prueba se hacía imposible sin caer en la adivinanza, por lo menos en la mayoría de los casos que llegan a juicio, donde no existe prueba autoevidente y determinante, sino que un conjunto de versiones subjetivas que, además, están integradas por

${ }^{13}$ Bentham, Jeremías, Tratado de las pruebas judiciales, Vol. I, traducción de Ossorio Florit, Manuel, Ediciones Jurídicas Europa-América, Buenos Aires, 1959, p. 191.

${ }^{14}$ Bentham, Tratado, cit. nota n. 13, p. 192. 
varios medios de prueba distintos que entregan cada uno solo un fragmento de la historia, como si fueran una ficha más de un rompecabezas mayor.

En este escenario se explica que el sistema escrito resolviera el problema de la valoración de la prueba de la manera más coherente con su realidad: si la opción política consistía en priorizar el control jerárquico (por medio de la escrituración) y su contrapartida era que el juez que recibía la información de manera escrita y mediata no estaba en condiciones de valorarla de una manera concreta, entonces se resolvió que la misma ley (o los criterios predefinidos del monarca) tomaran el lugar del juez, estableciendo un sistema de valoración que obviamente no podía ser concreto (es decir, no podía valorar la prueba después de haberse rendido, con todos sus matices) sino que a priori (antes de ser rendida) y en abstracto (en categorías generales). Esto es lo que se conoce como el sistema de prueba legal o prueba tasada, que surgió originalmente en el proceso romano posclásico "como llana expresión de autoritarismo y centralismo estatal". ${ }^{15}$

De acuerdo a este sistema, el juez/delegado sólo debía realizar los ejercicios previamente establecidos por la ley para concluir, independiente de su propio juicio, qué hechos debían darse por verdaderos. Así, frente a la pregunta "¿a quién debo creerle más?", la ley contestaba por categorías preestablecidas: si la declaración era de dos testigos contra uno, debía creer lo que dijeran los dos testigos porque "in ore duorum estat veritas (en boca de dos está la verdad)"16; si la declaración era de un pobre contra la de un hombre rico, debía creerle al rico porque "el pobre puede mentir por codicia o por promesa"17; si la declaración era la de un anciano en contra de la de un joven, debía creerle más al anciano porque "vieron más y pasaron más las cosas" ${ }^{18}$; si la declaración era la de un noble en contra de la de un villano, debía creerle más al noble porque "se guardará más de caer en vergüenza por sí, y por su linaje"19; y si la declaración era de una mujer en contra de la de un hombre, debía creerle al hombre porque "tiene el seso más firme"

Esta forma de proceder era también consistente con el objetivo de mantener el control del monarca. Ahora, además del control posterior de lo ya resuelto a

\footnotetext{
${ }^{15}$ Cappelletti, El Testimonio, cit. nota n. 4, p. 207.

${ }^{16}$ CAPPelletti, El Testimonio, cit. nota n. 4, p. 120. La misma regla se mantiene en el artículo 384 número 4 del Código de Procedimiento Civil chileno cuando señala que "Cuando los testigos de una y otra parte reúnan iguales condiciones de ciencia, de imparcialidad y de veracidad, tendrán por cierto lo que declare el mayor número".

${ }^{17}$ Cappelletti, El Testimonio, cit. nota n. 4, p. 170.

${ }^{18}$ Cappelletti, El Testimonio, cit. nota n. 4, p. 169.

${ }^{19}$ Cappelletti, El Testimonio, cit. nota n. 4, pp. 169 y 170.

${ }^{20}$ Cappelletti, El Testimonio, cit. nota n. 4, p. 170.
} 
través de la lectura del expediente, podía intervenir previamente en el mismo proceso de convicción del juez/delegado a través de reglas que intentaban obligarlo a arribar a las mismas conclusiones a las que hubiese llegado el monarca si hubiese conocido originalmente los antecedente ${ }^{21}$. Esta necesidad de control estricto demostraba la desconfianza "del legislador no sólo en el juez y en su capacidad de realizar una valoración libre y sagaz, sino más bien en el individuo mismo y en su dignidad, capacidad y honestidad" ${ }^{22}$.

El razonamiento que se usaba en estas reglas de la prueba (" $\mathrm{A}$ " es más creíble que " $B$ " porque " $\mathrm{A}$ " es hombre y " $\mathrm{B}$ " es mujer) era, por lo demás, muy propio de la época y ha sido caracterizado como un pensamiento escolástico ${ }^{23}$. En este razonamiento, se construyen máximas generales a partir de la experiencia, que luego son aplicadas a los casos concretos de manera absoluta, sin ningún control de validez para dichos casos específicos. Es un razonamiento grueso, muchas veces arbitrario y suele manifestar los prejuicios de cada época. Así se pueden explicar los ejemplos recién mencionados. La experiencia (o prejuicio) de la época decía, entonces, que un villano era más propenso a mentir que un noble y, por lo tanto, de acuerdo al pensamiento escolástico, siempre y sin excepción debía creérsele más a un noble que a un villano.

Por otra parte, el sistema de prueba legal requería también que existiera un catálogo cerrado de medios de prueba, es decir, que los hechos en un juicio sólo pudiesen ser demostrados a través de ciertos medios específicos que eran definidos previamente por la ley. De lo contrario, si se presentase un medio de prueba no regulado en la ley, el juez no dispondría de una valoración preestablecida para resolver posibles conflictos entre esa prueba y las demás que sí estaban reguladas. A los medios de prueba no regulados en la ley se los denominó "prueba atípica".

\section{c) Las inhabilidades en general}

Pero el sistema de la prueba legal no se limitaba a establecer reglas para valorar la prueba que efectivamente se podía rendir y acompañar al expediente, sino que también disponía inhabilidades. Esto significaba que a algunas personas se les impedía declarar. Por lo tanto, había ciertas personas a las cuales no sólo no debía creérseles, sino que derechamente no podía recibirse su testimonio.

\footnotetext{
${ }^{21}$ En este sentido Couture señala que "por acto de autoridad, se aspiraba a señalar de antemano el resultado de los procesos intelectuales del juez". Ver Couture, Fundamentos, cit. nota n. 3, p. 220.

${ }^{22}$ CAPpelletti, El Testimonio, cit. nota n. 4, p. 227. Al contrario, el sistema de valoración en concreto de la prueba ha sido calificado como un sistema "que supone la confianza del legislador hacia el juez en lo que atañe a la decisión sobre los hechos". Ver FERRER, La valoración, cit. nota n. 8, p. 61.

${ }^{23}$ Capelletti, Mauro, La oralidad y las pruebas en el proceso civil, Traducción de Sentís Melendo, Santiago, Ediciones Jurídicas Europa-América, Buenos Aires, 1972, especialmente pp. 93 a 95.
} 
Lo que ellos tuviesen que decir no podía ser escuchado ni tomado en cuenta por el juez a la hora de determinar la verdad de los hechos. Así, por ejemplo, las personas que hubiesen sido condenadas por un delito, los parientes de alguna de las partes y los ateos, entre otros, eran estimados testigos inhábiles y su testimonio no podía ser recibido.

Esto ocurría tanto en el sistema europeo continental como en el sistema de justicia inglés, donde paralelamente convivía el sistema del Common Law y el de Equity, aunque en el sistema inglés no se usaba la nomenclatura de la "inhabilidad" para declarar, sino que el de la "exclusión" de prueba. En ambos casos la razón para no recibir el testimonio de estas personas era exactamente la misma, como lo señalaba Jeremías Bentham, crítico de esta medida, al señalar que en Inglaterra esta "exclusión (...) se aplica a prevenir los errores de la justicia, es decir, a descartar los testimonios que se prejuzgan engañosos..."24.

En general, como lo manifestaba Bentham, los inhabilitados o excluidos para declarar eran todas personas respecto de las cuáles, en principio, se podía desconfiar y el sistema, por sus características de escrituración y delegación de funciones ${ }^{25}$, no estaba en condiciones de entregar al juez herramientas suficientes para superar ese prejuicio inicial, de la misma forma en que no estaba en condiciones de proporcionarle medios para valorar en concreto la información entregada por los testigos que sí estaban habilitados para declarar. Por lo tanto, derechamente "inhabilitar" o "excluir" a estas personas parecía coherente con las prioridades y limitaciones de este sistema. Además, este resultado era también consistente con el pensamiento escolástico descrito anteriormente.

\section{d) La inhabilidad de las partes para declarar}

Dentro del universo de personas inhabilitadas para declarar, un grupo importante eran todas aquellas que tuviesen un interés directo o indirecto en la resolución del conflicto. Por su puesto, una persona interesada, en principio, podría estar tentada a mentir en defensa de sus propios intereses o, al menos, en matizar u omitir toda información que la perjudicare, lo que la transformaba en una persona inhábil o excluible para declarar. ¿Cómo podría el juez del sistema escrito hacer un análisis fino de la credibilidad del relato de una persona interesada si nunca pudo presenciar su declaración? ¿Estará esa persona diciendo la verdad en este caso concreto, a pesar de su interés en el conflicto, o estará mintiendo o matizando los hechos en su favor, como lo señala la experiencia

\footnotetext{
${ }^{24}$ Bentham, Jeremías, Tratado de las Pruebas Judiciales, Vol. II, traducción de Ossorio Florit, Manuel, Ediciones Jurídicas Europa-América, Buenos Aires, 1959, p. 92.

${ }^{25}$ En el caso del sistema del Common Law inglés, la exclusión de esta prueba se justificaba en la protección del jurado. Sobre esto ver CAPpeLletti, Mauro, El testimonio de la parte en el sistema de la oralidad, Parte Segunda, Traducción de Banzhaf, Tomás A., Librería Editora Platense, La Plata, 2002, p. 12.
} 
general?26 De nuevo, consistente con las limitaciones del sistema escrito debido a la falta de una relación directa del juez con la prueba, la doctrina de la prueba legal resolvió entonces que "nemo ideoneus testis in re sua intelligitur (no se trata a nadie por testigo idóneo en causa propia)" ${ }^{\prime 27}$ y por lo tanto definió que sólo los terceros no interesados podían ser testigos hábiles ${ }^{28}$.

Como consecuencia directa de esta definición, las partes que formaban parte del conflicto no podían ser admitidas a declarar voluntariamente en su favor como testigos ya que eran las primeras interesadas en la resolución final de su propia controversia. La regla surgida entonces desde el razonamiento apriorístico fue sencilla: las partes tienen interés en la resolución de sus propios conflictos; los que tienen un interés quieren protegerlo; para protegerlo están dispuestos a mentir, matizar u omitir información en su defensa; por lo tanto, las partes son indignas de crédito y deben ser inhabilitadas (excluidas) para declarar voluntariamente a su favor siempre y en todos los casos.

Así, durante siglos, lo que las partes hubiesen percibido directamente por sus sentidos (lo que hubiesen visto o escuchado), no podía ser relatado por ellos mismos voluntariamente dentro del proceso judicial con valor probatorio, por lo que debían intentar ingresar la información de la que disponían a través de otros medios de prueba "no inhabilitados". Por su puesto, es fácil imaginar que esta limitación fomentara el uso de testimonios falsos para suplir la imposibilidad de entregar directamente la información que poseían, lo que además era alentado por la dificultad del mismo sistema para detectar la información de mala calidad debido a la ausencia de una relación directa entre el juez y la prueba que era, como ya se ha señalado, mediatizada por la escrituración y la delegación de funciones. Además era alentado por la ausencia de herramientas para que los mismos litigantes pudieran controvertir la prueba de manera efectiva demostrando con ello sus carencias al juez. Como consecuencia, la prueba testimonial tuvo gran descrédito y se sobrevaloró la prueba documental (aunque

\footnotetext{
${ }^{26}$ En esta misma línea, Chiovenda señala que "Lo que debe hacerse, como ha sucedido en las legislaciones más modernas, es despojar a la prueba testifical de su formalismo y poner al juez en la posición de ejecutar sobre ella un espíritu crítico, lo cual únicamente es posible en el proceso oral y concentrado". ChIOvenda, José, Principios de derecho procesal civil, Tomo II, Traducción de Casais y Santaló, José, Instituto Editorial Reus, Madrid, 1977, p. 326.

${ }^{27}$ Cappelletti, El Testimonio, cit. nota n. 4, p. 161.

${ }^{28}$ Así, Chiovenda define a los testigos como "la persona distinta de los sujetos procesales llamada a exponer al juez las propias observaciones de hechos acaecidos que tienen importancia en el pleito", Chiovenda, Principios, cit. nota n. 26, p. 323. Ver también Carneluttı, Francesco, La prueba civil, Traducción de Alcalá-Zamora y Castillo, Niceto, Ediciones Depalma, Buenos Aires, 2000, pp. 147 y ss. En Chile, Darío Benavente presenta esta definición de testigo de acuerdo al Código de Procedimiento Civil: "personas extrañas al pleito que deponen acerca de los hechos controvertidos" y señala que la inhabilitación de algunas personas para declarar se justifica "por presumir la ley su falta de imparcialidad". Benavente Gorroño, Darío, Derecho procesal civil, juicio ordinario y recursos procesales, quinta edición actualizada, Editorial Jurídica, Santiago, Chile, 2004, pp. 56 y 59, respectivamente.
} 
paradojalmente muchos documentos no sean otra cosa que la declaración de una persona puesta por escrito).

\section{e) La confesión}

Sin embargo, la imposibilidad de las partes para declarar no era total, sino que estaba limitada sólo a lo que ellas pudieran decir en beneficio de sus intereses (pro se declaratio), pues la sospecha ya no existía si estaban dispuestos a entregar información que los perjudicara (contra se declaratio). Por ello, si una parte entregaba información en contra de sus propios intereses, es decir, si confesaba, no era merecedor, a priori y en abstracto, de la misma desconfianza que producía su defensa. ¿Por qué, en principio, no creerle al que confiesa en detrimento de sus propios intereses? Al estar ausente la sospecha apriorística, el sistema de prueba legal permitió entonces que las partes pudieran confesar ${ }^{29}$.

De esta forma, el sistema de prueba legal se encargó de regular el mecanismo a través del cual debía producirse esta confesión como prueba en el proceso. Así, en grandes líneas, la declaración de la parte procedía si era forzada por la contraria, quien formalmente la citaba para obtener de ella una confesión mediante la absolución de posiciones (per positiones en el derecho italianocanónico e interrogatoire sur faits et articles en el francés). Las preguntas eran previamente escritas por la parte contraria que la había solicitado. También existía la confesión espontánea (no forzada) que consistía en la manifestación de hechos desfavorables a la parte expresados en su propio escrito de demanda o contestación. ${ }^{30}$ La confesión recibida debía ser valorada por el juez usando un intrincado sistema que clasificaba las confesiones en diversos grupos ${ }^{31}$ a los que podía asignarse distintos valores probatorios, pero que en resumen hacía vinculante para el juez sólo las declaraciones realizadas por la parte en contra de sus intereses y le negaba valor probatorio a las realizadas en su beneficio.

Como se puede apreciar, esta manera de permitir la declaración de la parte adolece, entre otros, del mismo problema que su prohibición: se trata de un criterio abstracto y a priori, sin cabida para los matices de la realidad ${ }^{32}$.

\footnotetext{
${ }^{29}$ En esta línea, Chiovenda define la confesión como "la declaración que hace una parte de la verdad de hechos afirmados por el adversario y favorables a éste". ChIOvendA, Principios, cit. nota n. 26, p. 306. Benavente la define como "el reconocimiento que la parte hace de un hecho que producirá consecuencias jurídicas en su contra en el proceso en el que se invoca como medio de prueba". BENAVENTE, Derecho, cit. nota n. 28, p. 71.

${ }^{30}$ Ver Benavente, Derecho, cit. nota n. 28, p. 74.

${ }^{31}$ Se distinguía entre confesión calificada, confesión simple, confesión compleja, confesión impura, etc. Ver Cappelletti, El Testimonio, cit. nota n. 4, p. 198 y pp. 245 y ss. Ver también Chiovenda, Principios, cit. nota n. 26, pp. 306 a 310.

${ }^{32}$ En este sentido, Taruffo ha señalado que "La justificación aducida habitualmente para justificar el efecto vinculante de la confesión es una especie de máxima del sentido común según la cual nadie admitiría la verdad de un hecho desfavorable a menos que tal hecho fuera verdadero. Sin embargo,
} 


\section{f) La recepción del sistema de prueba legal en nuestro ordenamiento}

El sistema escrito se traspaso desde la iglesia católica y el sistema feudal hacia los nuevos regímenes políticos republicanos. Desde España, uno de los países europeos que más tarde pasó de la escrituración a la oralidad ${ }^{33}$, Ilegaron sus leyes a América primero impuestas hacia las colonias y luego adquiridas voluntariamente como repúblicas independientes. Así, nuestro Código de Procedimiento Civil de 1902, sólo por nombrar uno, sancionado varias décadas después de la independencia y que rige en Chile hasta el día de hoy, incorporó entonces este sistema escrito, con delegación de funciones y prueba legal.

Aunque el sistema de prueba legal de los códigos republicanos es menos radical que el medieval, mantiene en lo fundamental una aproximación apriorística hacia la prueba. Así, por ejemplo, el artículo 384 del Código de Procedimiento Civil chileno que dispone, en su numeral 4, que "cuando los testigos de una y otra parte reúnan iguales condiciones de ciencia, de imparcialidad y de veracidad, (los jueces) tendrán por cierto lo que declare el mayor número". Respecto de las inhabilidades para declarar, el artículo 357 señala que son testigos inhábiles, entre otros, "los vagos sin ocupación u oficio conocido" y "los que en concepto del tribunal sean indignos de fe por haber sido condenados por delito", agregando el artículo 358 numeral 6 del mismo código que son inhábiles para declarar todos aquellos que "carezcan de la imparcialidad necesaria para declarar por tener en el pleito interés directo o indirecto".

\section{El alejamiento del sistema de prueba leGal en los sistemas comparados}

Las críticas al sistema de prueba legal no son nuevas. Ya en 1832 Jeremías Bentham, junto a otros importantes juristas, se oponía firmemente a él y ridiculizaba la inhabilitación o exclusión de los testigos por cuestiones relacionadas a su credibilidad. En particular, respecto de aquellos que eran inhabilitados para declarar en juicio por tener un interés, señalaba que "Si el interés, tomando la palabra en el sentido más general, representa una razón suficiente de exclusión, debe concluirse que todo testimonio procedente de labios humanos debiera

ésta es una justificación muy endeble: el mismo argumento sería más racional si se usara para proponer un estándar para la valoración discrecional del valor probatorio de la confesión de una de las partes, y no como el fundamento para justificar su efecto vinculante". TARUFFO, La Prueba, cit. nota n. 2, p. 73.

${ }^{33}$ En España rigió la Ley de Enjuiciamiento Civil de 1881, que contenía un sistema escrito, con delegación de funciones y prueba legal basado en las Siete Partidas, hasta la entrada en vigencia de la nueva Ley de Enjuiciamiento Civil del año 2000, aunque la Ley de Enjuiciamiento española de 1855 fue la primera en usar el término de "sana crítica" al definir la manera en que el juez debía valorar la prueba de testigos. Ver Couture, Eduardo, Estudios de Derecho Procesal Civil, Tomo II, $3^{\text {a }}$ edición, LexisNexis, Buenos Aires, 2003, p. 124. 
excluirse $^{\prime \prime 34}$. Más aun, respecto de la declaración de las partes en el juicio, Bentham, padre del que denominaba el "procedimiento natural" en contraposición al vicioso "procedimiento técnico", señalaba que "... al comienzo de una causa y luego de todas las veces que sea menester, las partes serán llamadas y escuchadas en carácter de testigos como de partes, cara a cara, en presencia del juez ${ }^{\prime \prime 35}$. Más cercano a nuestro tiempo, Cappelletti señalaba que el sistema de prueba legal era "un procedimiento que obviamente no puede ya corresponder a un pensamiento jurídico que alardea de haber abandonado (...) las abstracciones mecánicas deductivas típicas del pensamiento medieval y de la lógica Ilamada tradicional o aristotélico-tomista". Por último, Taruffo señala que la valoración en concreto de la prueba, cada vez más importante en todos los procesos civiles modernos, implica que "las normas jurídicas que restringen el uso de los medios de prueba deben ser reducidas al mínimo" ${ }^{\prime 36}$.

\section{a) La nueva idea que subyace al cambio}

No es de extrañar que Bentham, junto otros innovadores de su época y los que lo siguieron, impregnados por los avances de la ciencia y la nueva forma de pensamiento humano, hicieran estas afirmaciones y se opusieran al método de razonamiento escolástico subyacente en el sistema de la prueba legal. El nuevo pensamiento científico postulaba una forma muy distinta de aproximarse a los problemas: primero debía observarse al objeto de estudio para llegar a una conclusión y, una vez obtenida, para hacerla aplicable a otros casos, era necesario primero controlar la validez de la primera conclusión para el nuevo caso. Esta manera de razonar ha sido definida como un pensamiento concreto ${ }^{37}$ y su triunfo en el área procesal fue calificado como "la revancha de la observación directa de los datos y de la crítica libre sobre la superstición y el prejuicio, el triunfo del juicio concreto sobre el vinculado a la abstracta y apriorística valoración legal" ${ }^{\prime 3}$. Por lo mismo es que el juicio, esa audiencia en la que se reciben los medios de prueba y el juez forma su convicción, debía ser reformado para lograr que tuviese "un fuerte parecido de familia con el método científico en lo que se refiere a la aceptación de hipótesis" ${ }^{\prime 39}$.

\footnotetext{
${ }^{34}$ Bentham, Tratado, cit. nota n. 24, pp. 130 y 131.

35 Bentham, Jeremías, citado por Cappelletti, El testimonio, cit. nota n. 4, p. 46.

${ }^{36}$ TARuffo, La Prueba, cit. nota n. 2, pp. 24 y 25.

${ }^{37}$ Para más antecedentes sobre este punto, ver CAPELLetTI, La oralidad, cit. nota n. 23, p. 45.

${ }^{38}$ Salvioli, citado por Cappellettı, El testimonio, cit. nota n. 4, p. 104.

${ }^{39}$ Coloma Correa, Rodrigo, La Prueba en el Nuevo Proceso Penal Oral, Universidad Católica de Temuco, Santiago, 2003, p. 1. El autor hace esta afirmación no para prescribir cómo debe ser la audiencia de juicio, como se usa aquí, sino más bien para describir al juicio oral del nuevo Proceso Penal chileno.
} 
Si el pensamiento concreto era llevado al campo de las pruebas en los juicios, debía estimarse que no era racional concluir nada sobre la credibilidad de una declaración sin primero haberla recibido, como hacía el sistema de la prueba legal. Por el contrario, sólo una vez presenciada cada prueba (específica y única), podía sacarse alguna conclusión respecto de ella, ya fuera aplicándole las conclusiones obtenidas con anterioridad en casos similares o desechándolas al no ser válidas para ese caso concreto. Por lo tanto, la valoración de la prueba no podía ser legal (por el legislador a priori y en abstracto), sino que judicial (por el juez luego de ver y escuchar las pruebas únicas de cada caso). Así, en la declaración de una madre que era ofrecida para declarar a favor de su hijo, no resultaba lógico inhabilitarla o excluirla sólo porque la experiencia general dijera que "las madres mienten a favor de sus hijos". Por el contrario, para resolver cualquier asunto relacionado con su credibilidad, la madre debía ser primero escuchada para, luego, y sólo una vez que fuera recibido su testimonio y el de los demás testigos, expertos y prueba material, concluir que, como lo señala la experiencia "esta madre no es creíble y mintió para favorecer a su hijo" o, por el contrario, que esta madre en concreto dijo la verdad cuando declaró en beneficio de su hijo, ya fuera por la consistencia interna de su relato, su consistencia con los demás medios de prueba o por las razones justificadas que fueran aplicables al caso concreto.

A partir de estas ideas comenzó el proceso de alejamiento del sistema de prueba legal y, en particular, de la inhabilitación de los terceros interesados y las partes para declarar voluntariamente como testigos. Fue este, sin embargo, un proceso paulatino y con distinto énfasis en el sistema del Common Law y el Europeo-Continental.

\section{b) La evolución en los distintos sistemas legales}

A pesar de haber sido Francia la cuna de la revolución del pensamiento ilustrado, el primero en comenzar a alejarse de este método de una manera coherente y decidida en el tiempo fue el sistema inglés. En él convivían paralelamente dos sistemas judiciales: las Courts of Common Law, donde el órgano decisor era un jurado, y las Courts of Equity, que tenían su origen en el sistema canónico, donde el decisor era un juez y el proceso escrito. ${ }^{40}$ Aunque la influencia del sistema de la prueba legal tenía diferente intensidad en cada uno, en ambos sistemas se excluían las declaraciones de las partes y de los terceros directamente interesados a través de la disqualification of parties and interested

\footnotetext{
${ }^{40}$ Sobre algunos antecedentes históricos de ambos sistemas, ver Pérez-RAgone, Álvaro, "“Writ" y "Actio" en el surgimiento y la Configuración del Proceso Civil Inglés Medieval", Revista de Estudios HistóricoJurídicos XXIX, 2007, pp. 333 a 356.
} 
persons as witnesses (descalificación como testigos de las partes y otras personas interesadas). A partir de la Lord Demand's Act de 1843 fue derogada la exclusión como testigos de los terceros interesados, pero se mantuvo la exclusión de la declaración de la parte y de su cónyuge. Con la Country Courts Act de 1846 y la Evidence Further Amendment Act de 1869, entre otras, se aceptó que el juez o el jurado percibiera directamente por sus sentidos la declaración de las partes y de su cónyuge, siendo éstos sometidos al examen directo del abogado de la parte que lo presentaba y al contraexamen de la contraria, al igual que toda la prueba testimonial. Por supuesto, como puede advertirse, el sistema de las Courts of Equity fue reformada completamente, dando paso a la oralidad e inmediación en sus procedimientos ${ }^{41}$.

El sistema en Estados Unidos de América siguió rápidamente un camino similar al inglés. La legislación con mayor influencia en el resto de los Estados Americanos para eliminar la exclusión como testigos de las partes y los testigos interesados fue el Code of Civil Procedure del Estado de Nueva York de 1848. De ahí en adelante, los demás estados fueron paulatinamente eliminando la exclusión de las partes y de los terceros interesados como testigos. Las normas federales fueron las últimas en cerrar el círculo². Así, hoy la regla 601 de las Federal Rules of Evidence señala que "Toda persona es hábil para ser testigo, salvo los casos en que estas normas dispongan lo contrario"43. En los comentarios a esta regla del Advisory Committee on Rules, se señalaba que ella "elimina todas las bases para alegar falta de habilidad por razones que no hayan sido reconocidas específicamente en las normas que siguen en este artículo"44 y que "dentro de las razones para alegar la inhabilidad que fueron derogadas están el credo religioso, la condena por delitos, y la conexión con el juicio como parte o tercero interesado o como cónyuge de la parte o de un tercero interesado" 45 . Por lo mismo, "Es hábil para declarar todo testigo no experto que tenga cono-

\footnotetext{
${ }^{41}$ Para más información al respecto, ver el completo trabajo de CAPPELlettI, El testimonio, cit. nota n. 25. Ver también al mismo CAPELlettı, La oralidad, cit. nota n. 23, pp. 63 a 71.

${ }^{42}$ Para más detalles sobre las reformas en Estados Unidos de América, ver CAPPELletTI, El testimonio, cit. nota n. 25, pp. 37 y ss.

${ }^{43}$ Traducción libre del autor. La versión en inglés señala que "Every person is competent to be a witness except as otherwise provided in these rules". Ver Federal Rules of Evidence, Rule 601, disponible En: http://www.uscourts.gov/rules/Evidence_Rules_2007.pdif [visitado el 08/03/2010].

${ }^{44}$ Traducción libre del autor. La versión en inglés señala que "eliminates all grounds of incompetency not specifically recognized in the succeeding rules of this Article". Las notas del Advisory Committee on Rules pueden verse En: http://www.law.cornell.edu/rules/fre/ACRule601.htm [visitado el 08/03/2010].

${ }^{45}$ Traducción libre del autor. La versión en inglés señala que "Included among the grounds thus abolished are religious belief, conviction of crime, and connection with the litigation as a party or interested person or spouse of a party or interested person". Las notas del Advisory Committee on Rules pueden verse En: http://www.law.cornell.edu/rules/fre/ACRule601.htm [visitado el 08/03/2010].
} 
cimiento personal del hecho sobre el que declara"46. Si bien, como la misma regla 601 señala, siguen existiendo hasta hoy algunos casos en que se excluye la declaración de ciertas personas, ella no se produce por la falta de credibilidad a priori del testigo, sino que se trata de casos calificados que responden a una política legislativa racional. Así, los casos tratados en la Regla 605 y 606 sobre falta de idoneidad para ser testigo del juez y de los miembros del jurado del mismo caso en el que están ejerciendo como tales. Un caso que se acerca más a la lógica de la prueba legal es el Dead Man's Statute (Estatuto del Hombre Muerto). Esta institución se aplica sólo en juicios civiles (no penales) y prohíbe declarar a los testigos que tengan interés en el resultado del juicio si, y solo si lo hacen sobre comunicaciones o acuerdos que hayan tenido con el difunto que vayan en contra de los intereses de la masa hereditaria. Se justifica esta exclusión en que es muy difícil detectar la mentira cuando quien podría estar en condiciones de hacerlo no puede hablar pues ha fallecido. Esta exclusión sólo existe en algunos estados y no existe a nivel Federal ${ }^{47}$.

En el sistema europeo continental, por su parte, los avances fueron dispares. ${ }^{48}$ Austria fue uno de los primeros en abandonar la prohibición de valorar las declaraciones que las partes hicieran en su beneficio. Primero lo hizo en los procedimientos de baja cuantía ("bagatelarios") en 1873, cuya fuente de inspiración explícita fue el sistema inglés. ${ }^{49}$ Luego, en 1895 se aplicó a los demás procesos civiles cuando se aprobó el Código de Franz Klein. En el mensaje de la primera de dichas leyes se señalaba con gran claridad que no se comprendía cómo el testimonio a favor de la parte "debía continuar proscrito de ese proceso, cuando en el nuevo proceso civil dominaba el criterio de la oralidad y por consiguiente el principio de la libre valoración de las pruebas, que posibilitaba la utilización esmerada de todos los elementos susceptibles de contribuir a la credibilidad del hecho a probar" ${ }^{\prime \prime 0}$.

\footnotetext{
${ }^{46}$ Definición de "witness - competent witness" en Black's Law Dictionary, Second Pocket Edition, St. Paul, Minn., Estados Unidos, 2001, p. 770. Traducción libre del autor. La definición en inglés señala que "A lay witness who has personal knowledge of the subject matter of the testimony is competent to testify".

${ }^{47}$ El Dead Man's Statute es definido como "A law prohibiting the admission of a decedent's statement as witness in certain circumstances, as when an opposing party or witness seeks to use the statement to support a claim against the decedent's estate". Ver Black's Law Dictionary, cit. nota n. 46, p. 174.

${ }^{48}$ Taruffo señala que "la idea de un modelo homogéneo del proceso de civil law ha sido y sigue siendo una fictio conceptual que ha escondido y confundido la realidad efectiva de los principales ordenamientos de la Europa continental y de los que de algún modo derivan de ellos en Europa y otras partes del mundo". TARufFo, Michele, Sobre las fronteras, Escritos sobre la justicia civil, Traducción de Quintero, Beatriz, Editorial Temis S.A., Bogotá, Colombia, 2006, p. 75.

${ }^{49}$ Para mayor detalle del proceso de reforma austriaco, ver CAPPellettI, El Testimonio, cit. nota n. 25, pp. 70 y ss.

${ }^{50}$ Citado en Cappelletti, El Testimonio, cit. nota n. 25, p. 78.
} 
Por su parte, el procedimiento alemán fue reformado con el Código Federal de $1877^{51}$. En él se impuso la idea del sistema por audiencias para "el logro más coherente de la incorporación y apreciación de la prueba" para lo cual "El juez debía apreciar y valorar la prueba según los cánones de la libre apreciación" 52. El Código de 1877 fue precedido de varias reformas parciales en la misma línea, y su esfuerzo en esta área fue perfeccionado posteriormente con la reforma de 1933, antes de la entrada del régimen nazi, donde se "abolió el juramento de las partes e introdujo la Parteivernehmung como un medio para obtener elementos de prueba acerca de los hechos litigiosos" ${ }^{\prime 53}$. En la actualidad, la declaración de la parte en Alemania (Parteivernehmung) procede de diversas maneras, incluyendo su declaración voluntaria (§447), teniendo todas como denominador común que ellas son interrogadas igual que los testigos y lo que digan es valorado por el tribunal de acuerdo a las normas de la libre valoración de la prueba $(\S 453)^{54}$.

En España, el año 2000 comenzó a regir la nueva Ley de Enjuiciamiento Civil, derogando el antiguo procedimiento de 1881, cuyas normas fueron herencia de las Siete Partidas medievales..$^{55}$ En el código de 1881 existía la confesión bajo juramento decisorio o indecisorio ${ }^{56}$ al estilo del sistema de la prueba legal. Tanto este código como el Código Civil se encargaban de regular este medio de prueba y le concedían a priori y en abstracto el valor de "prueba plena" sólo contra su autor. A su vez, la confesión judicial estaba rodeada de diversas reglas: la confesión era indivisible, irrevocable y se prohibía la prueba de testigos contra los

\footnotetext{
${ }^{51}$ Para más información sobre el procedimiento alemán ver CAPPELLETTI, El Testimonio, cit. nota n. 25, pp. 120 y ss.; también TARUfFO, Sobre las fronteras, cit. nota n. 48, especialmente pp. 74 y ss.

52 Pérez-Ragone, Álvaro; Palomo Vélez, Diego, "Oralidad y Prueba: Comparación y análisis crítico de las experiencias reformadoras del proceso civil en Alemania y España", Revista de Derecho de la Pontificia Universidad Católica de Valparaíso XXXII, 2009, p. 367.

${ }^{53}$ TARUfFo, La prueba, cit. nota n. 2, p. 68.

${ }^{54}$ Las distintas formas en que se puede producir la declaración de la parte son las siguientes. En primer lugar, puede una parte solicitar la declaración forzada de la otra ( $\$ 445 \mathrm{ZPO})$. En este caso, la ley señala que esta solicitud sólo procederá cuando la parte que la pide sea la que tiene la carga de la prueba y no haya aun podido superarla. Además, el tribunal debe considerar que se trate de hechos que no han sido ya probados en sentido contrario. En segundo lugar, puede la misma parte solicitar su propia declaración ( $\$ 447 \mathrm{ZPO}$ ) siempre y cuando se trate de la parte que tiene la carga de la prueba y la contraria no se oponga, lo que generalmente no ocurre ya que si éste se opone ello podría ser valorado desfavorablemente por el tribunal. Por último, puede el tribunal ordenar de oficio la declaración de una o ambas partes (§ 448 ZPO). Para más detalles, ver Pérez-Ragone, Álvaro; Ortíz Pradillo, Juan Carlos, Código Procesal Civil alemán, Traducción con un estudio introductorio al proceso civil alemán contemporáneo, Fundación Konrad-Adenauer, 2006, disponible En: http://www.kas.de/wf/doc kas_9523-544-4-30.pdf [visitado el 08/03/2010]. Ver también TARUFFO, La prueba, cit. nota n. 2, p. 69; CAPElletti, El Testimonio, cit. nota n. 25, p. 211.

55 Pérez-Ragone; Palomo, "Oralidad", cit. nota n. 52, p. 370.

${ }^{56}$ Regulados en los artículos 580 y 581 de la Ley de Enjuiciamiento Civil española de 1881.
} 
hechos confesados. Si una confesión era prestada con todos sus requisitos, las demás pruebas resultaban irrelevantes. Esta situación era criticada por la doctrina. A su respecto se señaló que "Obviamente, la aplicación estricta de estas reglas hubiese conducido a situaciones de todo punto incompatibles con la finalidad del proceso, que no es otro que la resolución de un conflicto intersubjetivo, mediante la determinación de la verdad y sin menoscabo de terceros ${ }^{\prime \prime 57}$. Por lo mismo, incluso antes de la reforma del año 2000, el Tribunal Supremo español comenzó a relativizar la fuerza vinculante del valor probatorio de este medio de prueba para el juez ${ }^{58}$. Con la nueva ley de Enjuiciamiento Civil de 2000 se avanzó en la dirección de la valoración en concreto: las partes debían declarar directamente ante el juez, las preguntas debían ser realizadas de manera oral (art. 302) y la declaración de la parte a su favor podía ahora ser valorada por el juez, lo que además debía hacer de acuerdo a las reglas de la sana crítica (art. $316 N^{\circ} 2$ 2). Sin embargo, este avance fue parcial: sólo se reguló la declaración forzada de la parte (no en cambio su declaración voluntaria) y los hechos confesados que fuesen enteramente perjudiciales a ella debían ser considerados como ciertos obligatoriamente por el juez ${ }^{59}$. Con esta norma se mantuvo el sistema de prueba legal, al menos en esta hipótesis. Lo anterior, ya bastante claro por sí mismo, se reafirma al conocer su justificación: la regla "descansaría sobre la máxima de experiencia" consistente en que "cuando una persona reconoce hechos personales que le perjudican tiene que ser creída adquiriendo certeza los hechos incluso sobre aquellos deducidos por el juez" ${ }^{\prime \prime 0}$. Esta explicación ha sido

\footnotetext{
57 Medina Cepero, Juan Ramón, "La Valoración Judicial del interrogatorio de las partes en el Proceso Civil", en Repertorio de Jurisprudencia núm. 18/2003 (Estudio), Editorial Aranzadi S.A., Pamplona, 2003, p. 2 de la edición electrónica Westlaw España.

${ }^{58}$ Ver sentencia de la Sala $1^{\text {a }}$ del Tribunal Supremo de 5 de noviembre de 1996 (RJ 1996, 9276), donde se señala que si "se atribuye a la confesión una elevada fuerza probatoria es porque hay una presunción indudable de que cuando se afirma que perjudica al que declara, es que el hecho a que se refiere es verdad en sentido material, por más que se traduzca en los autos en una verdad formal, sin perjuicio todo ello de poder ser desvirtuada por el resultado de otros medios probatorios...". Ver también sentencia de la Sala $1^{\text {a }}$ del Tribunal Supremo de 20 de diciembre de 1994 (RJ 1994, 9772) que señala "la confesión en juicio prestada bajo juramento indecisorio no es de rango superior a los demás medios demostrativos citados en el artículo 1215 del Código Civil (...) y su eficacia ha de ser apreciada libremente en conjunción con el resultado que arrojen las restantes pruebas, sometidas todas ellas a la libre y racional valoración de los Tribunales, amén de que en virtud del principio de indivisibilidad de aquélla, su fuerza probatoria hay que referirla al conjunto armónico de lo confesado y no a la estimación fragmentaria de las posiciones".

${ }^{59}$ Para que esta valoración legal fuese aplicable, el confesante debía haber declarado sobre (1) hechos en los que intervino personalmente, y (2) que su declaración no haya sido contradicha por el resultado de las demás pruebas. Ver el artículo 316 № 1 de la Ley de Enjuiciamiento Civil 1/2000 española.

${ }^{60}$ Montero Aroca, Juan, citado por Lorenzo de Membiela, Juan B., "Estudio sincrético del interrogatorio de las partes en la LPL/1995", en Sentencias de TSJ y AP y otros Tribunales núm. 12/2003 (Comentario), Editorial Aranzadi, S.A., Pamplona, 2003, p. 8 de la edición electrónica Westlaw España.
} 
calificada como "muy endeble" porque "el mismo argumento sería más racional si se usara para proponer un estándar para la valoración discrecional del valor probatorio de la confesión de una de las partes, y no como el fundamento para justificar su efecto vinculante" ${ }^{\prime \prime 1}$.

Francia, por su parte, fue gran precursor de muchas de las reformas en los demás ordenamientos y cuna del pensamiento crítico que llevó, entre otras cosas, al decaimiento del sistema de la prueba legal, permitiendo la declaración voluntaria de las partes. Por ello, en el comienzo, fue considerado "un ejemplo de la realización de un sistema oral" "62. El Code de Procédure Civil de 1806 disponía originalmente dos formas diferentes de declaración de las partes con efectos probatorios ${ }^{63}$ : La comparution personnelle (comparecencia personal) y el interrogatoire sur faits et article (interrogatorio de hechos y artículos). Este último respondía al método formal de la absolución de posiciones donde la declaración de la parte era forzada, recibida por un juez delegado, sin presencia de la contraparte y respondiendo a preguntas redactadas con anterioridad. Su rigidez e ineficacia hizo que poco a poco fuera cayendo en desuso, especialmente si existía otro mecanismo más sencillo y eficaz, como la comparecencia personal de las partes. Por lo mismo, el interrogatoire sur faits et article fue finalmente derogado en 1942. En cambio, la comparecencia personal, que existe hasta hoy, se realizaba sin mayores formalidades, en presencia de la contraparte, frente al juez o tribunal del juicio, permitiendo que éste pudiera formarse una opinión directa del medio de prueba ${ }^{64}$. Respecto del valor de la declaración de las partes, el artículo 198 del Code de Procédure Civil señala que "El juez puede sacar toda consecuencia de derecho de la declaración de las partes, de la inexistencia o de la negación de responder de una de ellas y hacerlo como equivalente a un comienzo de prueba por escrito" ${ }^{65}$. De acuerdo a Taruffo, esto significa que el juez puede dar a la declaración de la parte pleno valor probatorio ya que es valorada de manera discrecional ${ }^{66}$.

En Italia, existe el interrogatorio libero de las partes que se usa con tres objetivos: (1) clarificar el objeto del litigio, (2) permitir un arreglo voluntario entre

\footnotetext{
${ }^{61}$ Taruffo, La Prueba, cit. nota n. 2, p. 73.

${ }^{62}$ Cappelletti, El Testimonio, cit. nota n. 25, p. 357.

${ }^{63}$ La comparution personnelle puede ser usada tanto como declaración de parte con valor probatorio como también para aclarar sus alegaciones (fijar el objeto del juicio). Sobre esto, ver Cappellettı, El Testimonio, cit. nota n. 25, pp. 368 y ss.

${ }^{64}$ Para mayor detalle sobre la declaración de la parte en el sistema francés, ver CAPPELletTI, El Testimonio, cit. nota n. 25 , pp. 355 y ss.

${ }^{65}$ Traducción libre del autor. El artículo 198 señala en su forma original que "Le juge peut tirer toute conséquence de droit des déclarations des parties, de l'absence ou du refus de répondre de l'une d'elles et en faire état comme équivalent à un commencement de preuve par écrit".
}

${ }^{66}$ TARuffo, La Prueba, cit. nota n. 2, p. 70. 
las partes y, (3) obtener respuestas de las partes sobre hechos controvertidos, pero su valor como medio de prueba es mínimo y preestablecido por la ley, por lo que "está claro que el interrogatorio libero no es un medio para obtener un testimonio de las partes y sólo eventualmente puede constituir prueba adicional sobre los hechos litigiosos" ${ }^{\prime \prime}$. Además existe la confesión, es decir, la tradicional declaración forzada de la parte que "no cuenta como prueba a su favor. Sí cuenta en cambio como prueba en su cargo..."68. Esta manera de tratar la confesión ha sido calificada como "una reliquia del pasado que sigue existiendo simplemente por la inercia de algunos legisladores europeos" ${ }^{\prime 69}$.

Como se puede apreciar del somero repaso de la situación de la declaración de las partes en estos ordenamientos, la regla general ha sido tender hacia la valoración de la prueba en concreto, ya sea a través de la sana crítica o la libre valoración, y a que la declaración de la parte a su favor pueda ser valorada también por el tribunal, ya sea a través de su declaración forzada o de su declaración voluntaria.

\section{LAS REGLAS DE LA PRUEBA DE LOS NUEVOS SISTEMAS}

POR AUDIENCIAS PERMITEN LA DECLARACIÓN VOLUNTARIA DE LAS PARTES

Nuestros nuevos sistemas procesales han seguido la tendencia de los ordenamientos modernos, alejándose del sistema escrito y de la prueba legal. Como consecuencia, las nuevas reglas de la prueba del procedimiento de Familia y Laboral no establecen inhabilidades para declarar. Por el contrario, permiten que las partes puedan declarar como testigos en sus respectivos juicios. Lo anterior, sin embargo, no está establecido explícitamente. Esta conclusión se desprende de las normas que disponen que los jueces de ambos procedimientos deben valorar la prueba en concreto (sana crítica), lo que ya es un argumento fuerte por sí mismo, y también de las demás reglas de la prueba pormenorizadas que apuntan claramente en el mismo sentido y que forman un todo armónico en esa dirección, como se revisará a continuación.

\section{a) Reglas para la admisión de la prueba al juicio}

Los procedimientos de Familia y Laboral fueron diseñados con una audiencia previa a la de juicio, la audiencia preparatoria. Entre otros, ella tiene por objeto que el juez decida qué medios de prueba, de entre todos los ofrecidos por las partes, efectivamente serán admitidos y cuáles, en cambio, serán excluidos. En

\footnotetext{
${ }^{67}$ Taruffo, La Prueba, cit. nota n. 2, p. 71.

${ }^{68}$ Sitio Web de la Comisión Europea http://ec.europa.eu/civiljustice/evidence/evidence_ita_es.htm [visitado el 09/03/2010].

${ }^{69}$ TARUfFo, La Prueba, cit. nota n. 2, p. 73.
} 
esta labor de exclusión el juez no tiene amplia libertad, sino que debe ceñirse a los criterios señalados en la ley.

El primer criterio básico para resolver si un medio de prueba debe ser admitido para el juicio es el de la pertinencia ${ }^{70}$. Así, la ley de Tribunales de Familia establece que la prueba "manifiestamente impertinente" será excluida.71 Contrario sensu, para ser admitida, la prueba debe ser pertinente. El Código del Trabajo, por su parte, establece que "El juez resolverá fundadamente en el acto sobre la pertinencia de la prueba ofrecida por las partes..." ${ }^{72}$, pudiendo excluir la que no lo sea.

El examen de pertinencia se dirige básicamente a contestar la pregunta de si la prueba sirve para hacer más posible la versión de los hechos que sostiene la parte que la ofrece. Este es un examen de carácter lógico que deja de lado la pregunta sobre la credibilidad de la prueba, limitándose a responder la siguiente pregunta: si la prueba fuese presentada y creída en el juicio, la información que contiene ¿sirve para hacer más posible que los hechos hayan ocurrido de la manera que sostiene la parte que la ofrece? Si la respuesta es afirmativa, la prueba es pertinente y debe ser admitida. Si la respuesta es claramente negativa, la prueba es impertinente y debe ser excluida. Si la respuesta no es clara, la prueba debe ser admitida ya que debe favorecer a la parte que la presenta pues ella tiene mayor conocimiento de su caso y tiene el derecho subjetivo a presentar prueba. Esto queda más claro en materia de Familia ya que la ley expresamente señala que sólo puede excluirse aquella "manifiestamente" impertinente, por lo que si la prueba no es clara o patentemente impertinente, debe admitirse ${ }^{73}$.

El análisis de pertinencia, entonces, no dice ninguna relación con la credibilidad de la prueba. De hecho, en el ejercicio meramente lógico que debe realizar el juez, la credibilidad de la prueba es un supuesto, un pie forzado. ${ }^{74}$ El juez debe asumir, en este momento, que la prueba es creíble. A partir de allí

\footnotetext{
${ }^{70}$ Para más información sobre el significado de "pertinencia", ver TARUfFo, La Prueba, cit. nota 2, p. 38; también FERRER, La valoración, cit. nota n. 8, pp. 42 y 68.

${ }^{71}$ El artículo 31 de la Ley № 19.968 de Tribunales de Familia señala: "Exclusión de prueba. El juez de familia, luego de estudiar la admisibilidad de las pruebas ofrecidas, de resolver las convenciones probatorias y de escuchar a las partes que hubieren comparecido a la audiencia preparatoria, ordenará fundadamente que se excluyan de ser rendidas en el juicio aquellas que fueren manifiestamente impertinentes, tuvieren por objeto acreditar hechos públicos y notorios, resulten sobreabundantes o hayan sido obtenidas con infracción de garantías fundamentales. Las demás serán admitidas y se ordenará su rendición en la audiencia de juicio respectiva".

${ }^{72}$ Artículo 453 numeral 4 del Código del Trabajo.

${ }^{73}$ El mismo estándar de exclusión por impertinencia está establecido en el artículo 276 del Código Procesal Penal.

${ }^{74}$ Sobre esto, ver TARUfFo, Michelle, La prueba de los hechos, Traducción de Ferrer, Jordi, Editorial Trotta, Madrid, 2002, p. 366.
} 
puede formularse la pregunta de pertinencia. Por lo tanto, no puede excluirse por impertinente una prueba por ser parcial, falsa o poco confiable. Esto no significa que la pregunta sobre la credibilidad de la prueba no tenga importancia, sino sólo que dicha pregunta (si la prueba es o no creíble por alguna razón) está reservada para otro momento: la audiencia de juicio. Será el juez de fondo quien pueda contestar a esta pregunta sólo una vez que haya percibido la prueba, y toda la prueba, directa y personalmente en el juicio.

Pero la pertinencia de la prueba no asegura que ella sea admitida. Es decir, la pertinencia es un requisito necesario, pero no suficiente para ser llevada al juicio. Así, una prueba pertinente puede ser igualmente excluida por alguna de las otras causales de exclusión establecidas en la ley, como la prueba obtenida por medios ilícitos, los medios de prueba sobreabundantes o la que recaiga sobre hechos públicos y notorios. Sin embargo, tampoco estas otras razones de exclusión tienen relación alguna con la credibilidad de la prueba, sino que con cuestiones diversas, como la remoción de los incentivos para que las partes o sus abogados intenten ganar sus casos obteniendo prueba ilícitamente (prueba ilícita) o evitar perder recursos humanos y materiales del sistema judicial escuchando prueba innecesaria (prueba sobreabundante, sobre hechos públicos y notorios).

Por lo tanto, desde el punto de vista normativo, no existe una causa legal para excluir la declaración de la parte, como medio de prueba, en la audiencia preparatoria por razones de credibilidad. Podría ser excluida por impertinente, pero resulta poco probable que, al menos en la mayoría de los casos, lo que haya percibido directamente por sus sentidos uno de los protagonistas del conflicto no sirva para hacer más posible la versión de los hechos que plantea. De todas formas, esta impertinencia debe ser discutida caso a caso, de acuerdo al contenido propio de cada declaración, y no como una regla apriorística y abstracta que no está contemplada en la ley.

\section{b) Libertad de medios de prueba}

Ambos procedimientos, Familia y Laboral, disponen que las partes pueden valerse de cualquier medio de prueba de que dispongan para probar los hechos pertinentes y controvertidos que alegan, sin excluir a las partes mismas.

Así, en materia de Familia, el artículo 28, titulado "Libertad de prueba", dispone que "Todos los hechos que resulten pertinentes para la adecuada resolución del conflicto familiar sometido al conocimiento del juez podrán ser probados por cualquier medio...". El artículo 54, por su parte, entrega lo que podría ser una definición general de "medio de prueba", señalando que lo será "cualquier medio apto para producir fe", siendo evidente que lo que digan las partes, protagonistas del conflicto, es apto para producir fe, salvo que se siga la lógica escolástica medieval por la cual se concluye que todas las partes mienten, 
sin excepción, porque tienen interés en el conflicto, no pudiendo depositarse en ellas fe alguna.

En materia laboral, por su parte, el numeral 4 del artículo 453, que regula la admisibilidad de la prueba, señala que "El juez resolverá fundadamente en el acto sobre la pertinencia de la prueba ofrecida por las partes, pudiendo valerse de todas aquellas reguladas en la ley", agregando que "Las partes podrán también ofrecer cualquier otro elemento de convicción que, a juicio del tribunal, fuese pertinente". Es decir, las partes pueden ofrecer presentar en el juicio cualquier elemento de prueba, esté o no regulado expresamente en la ley, siempre y cuando cumpla con ser pertinente, requisito que, como se ha explicado, no se relaciona con la credibilidad de la prueba. Lo anterior se reafirma con lo señalado en el numeral 1 del artículo 454, que regula el orden en que cada parte debe presentar en el juicio los medios de prueba que ofreció anteriormente: "El orden de recepción de las pruebas será el siguiente: documental, confesional, testimonial y los otros medios ofrecidos".

Por lo tanto, en ambos sistemas, las reglas de la prueba reafirman que no existe un catálogo cerrado de medios de prueba, como en el sistema de la prueba legal, sino que, como es coherente con un sistema de valoración en concreto, cualquier medio que proporcione información pertinente puede ser usado en el juicio para lograr la convicción del tribunal. Así, ya siendo difícil negar la importancia que generalmente tendrá la información aportada por los protagonistas del conflicto, la misma ley deja abierto el espacio para que pueda ser entregada voluntariamente por ellos mismos.

\section{c) Regulación sobre la incorporación al juicio de la prueba no regulada explícitamente}

En materia de Familia, una vez definido qué medios pueden ser usados para probar un hecho en juicio (los regulados expresamente en la ley y cualquier otro pertinente), la ley se aboca a regular cómo esos medios de prueba deben ser producidos o incorporados a la audiencia, ya que, de acuerdo al mismo artículo 28, aunque cualquier medio puede ser usado para probar un hecho, todos deben producirse "...en conformidad a la ley". Así, se regula explícitamente cómo se debe producir la prueba de testigos, la declaración forzada de la parte que ha sido citada por la contraria y la declaración de los peritos. Nada se dice explícitamente sobre la declaración voluntaria de la parte, pero respecto de los medios de prueba cuya forma de producción no fue regulada explícitamente, la ley señala, en el inciso final del artículo 54, que "El juez determinará la forma de su incorporación al procedimiento, adecuándola, en lo posible, al medio de prueba más análogo".

En igual sentido, en materia Laboral, al definir cómo se debe producir la prueba en el juicio, la ley también reglamenta sólo las tradicionales (testigos, 
peritos, etc.), disponiendo en el numeral 8 de su artículo 458, que "Cuando se rinda prueba que no esté expresamente regulada en la ley, el tribunal determinará la forma de su incorporación al juicio, adecuándola, en lo posible, al medio de prueba más análogo".

Las normas anteriores confirman que no existe un catálogo cerrado de medios de prueba, sino que se puede utilizar cualquier medio que sirva para acreditar un hecho pertinente en el juicio, sin excluir la declaración de las mismas partes, entregando ahora también la respuesta a la pregunta sobre cómo debe producirse su declaración. En el caso de la declaración voluntaria de las partes, como se propondrá más adelante, la forma de producirla será usando las reglas de la prueba testimonial.

\section{d) No existen inhabilidades para declarar}

En el área de las reglas de la prueba más importante para efectos de este trabajo, la ley en materia de Familia señala explícitamente en su artículo 40, respecto de las personas que han percibido hechos pertinentes directamente a través de sus sentidos (los testigos), que "En el procedimiento de familia no existirán testigos inhábiles". Es decir, que en este procedimiento los testigos no pueden ser excluidos del juicio por razones de credibilidad, sino que todos deben ser primero escuchados por el tribunal, para luego darles peso probatorio concreto a su declaración. Consistente con esto, la ley le da la posibilidad a los litigantes de producir la "materia prima" con la cual el juez podrá posteriormente realizar su análisis de valoración: "las partes podrán dirigir al testigo preguntas tendientes a demostrar su credibilidad o falta de ella, la existencia de vínculos con alguna de las partes que afectaren o pudieren afectar su imparcialidad, o algún otro defecto de idoneidad".

Por su parte, el procedimiento laboral, en su artículo 454 numeral 5, señala que "No se podrá formular tachas a los testigos". Esta norma podría ser entendida como una derogación explícita de la inhabilitación para declarar por razones de credibilidad ya que en el sistema escrito "tachar" a un testigo era sinónimo de eliminarlo de la lista de testigos por razones de credibilidad. Sin embargo, esta norma parece estar más bien destinada a señalar que en el nuevo procedimiento laboral ya no es necesario seguir la formalidad de señalar expresamente al tribunal que se solicita la "tacha" del testigo en el mismo momento en que se está produciendo su declaración, como era la práctica antes de la reforma. Esto se desprende del mensaje de la ley donde se señala que "Se elimina, como trámite, la tacha de testigos, que en la actualidad puede dar lugar a incidencias dilatorias que entorpecen la marcha del juicio..." ${ }^{75}$.

${ }^{75}$ Historia de la Ley $\mathrm{N}^{\circ}$ 20.087, p. 19, disponible En: http://www.bcn.cl/histley/lfs/hdl-20087/HL20087. pdif [visitado el 08/03/2010]. Destacado en cursiva por el autor. 
Al ser eliminada la "tacha" sólo como trámite, ¿significa que no se eliminó su sustancia?, ¿significa que en el nuevo procedimiento laboral hay testigos inhábiles?, ¿significa que el tribunal igualmente puede "tachar testigos", es decir, no valorar la declaración de un testigo, pero en un momento posterior, como en la sentencia? La respuesta debe ser negativa. Un juez laboral no puede declarar inhábil a un testigo, sino que siempre debe admitir y valorar su declaración, dándole más o menos valor en concreto, como lo señala otra norma, el artículo 459 , al establecer en su numeral 4 que uno de los contenidos mínimos y obligatorios que debe tener toda sentencia definitiva en materia laboral es "El análisis de toda la prueba rendida, los hechos que estime probados y el razonamiento que conduce a esta estimación". Por lo tanto, todos los testigos deben ser valorados judicialmente (ex post y en concreto) de acuerdo a su propio mérito, sin importar que tengan interés directo o indirecto en el resultado del juicio. En este sentido, la norma del artículo 454, al señalar que "No se podrá formular tachas a los testigos", significa que los litigantes no deben entregar argumentos al tribunal sobre el valor probatorio que éste debe dar a la declaración del testigo mientras se realiza su interrogatorio. Así, por ejemplo, si durante el examen de un testigo, el abogado dijera al tribunal que "solicito a Su Señoría que estime que este testigo no está diciendo la verdad porque tiene interés en este juicio", estaría realizando una actividad impertinente.

La inexistencia de inhabilidades para declarar en materia laboral se confirma en la segunda parte de la misma norma en comento. El numeral 5 del artículo 454, luego de señalar que "No se podrá formular tachas a los testigos", dispone que "Únicamente en la oportunidad a que se refiere el número 9 de este artículo, las partes podrán hacer las observaciones que estimen oportunas respecto de sus circunstancias personales y de la veracidad de sus manifestaciones". Es decir, el hecho de no existir "tachas" no significa que a la persona que declara no puedan hacérsele preguntas que revelen al tribunal, por ejemplo, su parcialidad. Si fuera así, el tribunal carecería de elementos para valorar la prueba en concreto y no le quedaría otra alternativa que aplicar máximas apriorísticas. En palabras simples, no tendría "materia prima" con la cual trabajar para producir "valoración en concreto". Por lo mismo, esta norma sólo significa que el momento para analizar el valor de las respuestas del declarante debe hacerse en un momento posterior, en la oportunidad del "número 9 de este artículo", que es el momento de los alegatos de cierre, donde las partes "formularán, oralmente, en forma breve y precisa, las observaciones que les merezcan las pruebas rendidas y sus conclusiones ${ }^{\prime \prime 7}$. Esto es del todo coherente con un sistema de valoración en concreto porque los argumentos sobre el valor que debe darse a

${ }^{76}$ Artículo 454 numeral 9 del Código del Trabajo. 
la prueba deben realizarse cuando toda la prueba ya se ha rendido, de acuerdo al conjunto de la información aportada y no individualmente.

También puede argumentarse que no existen inhabilidades para declarar en materia laboral ya que no existe ninguna mención a ellas en las normas de su procedimiento. Ellas están contenidas ahora sólo en el Código de Procedimiento Civil que, a pesar de ser norma supletoria "en todo lo no regulado por este Código" "77, se aplican sólo si ellas no son "contrarias a los principios que informan este procedimiento" ${ }^{\prime \prime 8}$, y los principios que informan al procedimiento laboral son la oralidad y la inmediación, que contienen a su vez la sana crítica, método de valoración en concreto que pugna derechamente contra las inhabilidades para declarar surgidas del sistema de prueba legal, como se tuvo ya oportunidad de explicar.

\section{e) Método de valoración de la prueba}

La ley en materia de Familia señala que la forma de valorar la prueba presenciada por el juez será en concreto (judicial), al señalar en su artículo 32, titulado "Valoración de la prueba", que "Los jueces apreciarán la prueba de acuerdo a las reglas de la sana crítica. En consecuencia, no podrán contradecir los principios de la lógica, las máximas de la experiencia y los conocimientos científicamente afianzados".

El nuevo procedimiento laboral también dispone un método de valoración de carácter judicial, concreto, ex post. Así lo define el artículo 456 al señalar que "El tribunal apreciará la prueba conforme a las reglas de la sana crítica", agregando que "Al hacerlo, el tribunal deberá expresar las razones jurídicas y las simplemente lógicas, científicas, técnicas o de experiencia, en cuya virtud les asigne valor o las desestime".

Es decir, se trata de procedimientos en los que la prueba sólo se valora una vez que fue percibida directa y personalmente por el juez. Las máximas de la experiencia se aplican a una prueba en concreto ya percibida, si esto resulta válido para ese caso, y no antes de haberla presenciado. No hay, por tanto, prejuicios respecto de la credibilidad de la prueba.

\section{f) La declaración forzada de las partes}

En ambos procedimientos, Laboral y Familia, uno de los medios de prueba regulado explícitamente es la declaración forzada de la parte. Cualquiera de ellas puede citar a la otra, sin más requisitos que ser pertinente. En el procedimiento laboral se mantuvo para nombrarla la nomenclatura del sistema de

${ }^{77}$ Artículo 432 del Código del Trabajo.

${ }^{78}$ Artículo 432 del Código del Trabajo. 
prueba legal ("absolución de posiciones", "confesión"79) y en el de familia se modificó ("declaración de las partes" "so).

En ambos casos, no existe una regulación distinta a la general para valorar las declaraciones que las partes hayan realizado al declarar forzadamente. Por lo tanto, de acuerdo a la regla general de valoración en concreto de acuerdo a la sana crítica, el juez puede dar valor probatorio a todo lo que la parte citada por la contraria haya dicho. Es decir, el juez puede creer los dichos de la parte, hayan sido estos contrarios a sus intereses o en su favor.

En el sistema de la prueba legal la justificación para obligar al juez sólo a dar valor a lo que la parte dijera en contra de sus intereses era la desconfianza a priori en la veracidad de sus dichos. Por ello no podía darle valor, en cambio, a lo que dijera en su beneficio. Si ahora lo que la parte diga en su beneficio cuando declara forzadamente puede ser valorado a su favor por el tribunal, ¿qué sentido tendría mantener la prohibición para que declare voluntariamente?, ¿cuál podría ser el sustento, ya ni siquiera normativo, sino que puramente lógico, para continuar impidiéndole declarar voluntariamente? El hecho de que lo que diga la parte en su declaración forzada pueda ser usado por el juez en beneficio de esa parte es otro argumento más para demostrar que en estos procedimientos la parte puede declarar voluntariamente.

\section{Respuesta a lOS ARGUMENTOS}

CONTRARIOS A LA DECLARACIÓN VOLUNTARIA DE LAS PARTES

A partir de lo analizado hasta ahora, puede contestarse a los argumentos que se han esgrimido para mantener la limitación de las partes para declarar voluntariamente en el contexto de la implementación de estos nuevos sistemas ${ }^{81}$ :

1. "Las partes no pueden ser testigos porque no son terceros ajenos e imparciales":

En un sistema de libre valoración de la prueba los testigos no son definidos de esa manera. Un testigo es toda persona que ha percibido hechos pertinentes por sus sentidos. La definición de testigo como "tercero ajeno e imparcial" es propia del sistema de prueba legal que valoraba la prueba a priori y en abstracto, en el cual las inhabilidades constituían un prejuicio sobre la credibilidad de ciertas personas, explicado por la imposibilidad del juez de tener contacto directo con la prueba. En los sistemas de valoración en concreto no se prejuzga la credibilidad ni se aplican máximas en abstracto, sino que se juzga la credibilidad en

\footnotetext{
${ }^{79}$ Ver artículo 453 numeral 8 y artículo 454 numerales 1 , 4 y 10.

${ }^{80}$ Ver artículo 50 y ss. de la Ley № 19.968 de Tribunales de Familia.

${ }^{81}$ Estos argumentos han sido recibidos por el autor de parte de algunos jueces y abogados al participar en las capacitaciones y cursos realizados para la implementación de estas reformas.
} 
concreto, luego de haber recibido la prueba personalmente, aplicando máximas en concreto sólo luego de verificar si son válidas para ese caso específico.

2. "La inhabilidad de las partes para declarar sigue existiendo en los nuevos sistemas reformados porque no se señala expresamente lo contrario":

Aunque puede criticarse la falta de una norma expresa que dispusiera explícitamente la inexistencia de inhabilidades de las partes para declarar voluntariamente, ello es sólo porque estratégicamente hubiese sido conveniente hacerlo tomando en cuenta que nuestra cultura legal está fuertemente influida por el sistema de la prueba legal, por lo que las señales claras hubiesen sido preferibles para facilitar el cambio de prácticas. Sin embargo, aunque la norma expresa no exista, ella surge clara desde el significado y objetivos de la sana crítica (valoración en concreto) y de un sinnúmero de disposiciones positivas expresas de ambos ordenamientos que llevan a concluir necesariamente que ya no existen razones de lógica ni legales para inhabilitar a ningún testigo, incluidas las partes, por razones de credibilidad. En este contexto, la pregunta es más bien la contraria: ¿Cuál es la norma expresa que prohíbe a las partes declarar voluntariamente?

3. "La única forma en que el juez puede valorar lo que digan las partes es a través de su declaración forzada ('absolución de posiciones' o la 'declaración de las partes'), porque esa es la única regulación legal que existe":

Los sistemas de sana crítica permiten, en concordancia con la finalidad de valorar en concreto, que los hechos pertinentes en un juicio sean probados a través de cualquier medio. No existe, como en el sistema de prueba legal, un catálogo cerrado y excluyente de medios de prueba. Por lo tanto, el hecho de que el legislador haya regulado explícitamente la "absolución de posiciones" o la "declaración de las partes" como medio de prueba, no es argumento suficiente para sostener que los demás estén excluidos, como ocurriría con la declaración voluntaria de la parte. De hecho, la declaración voluntaria de la parte y su declaración forzada pueden coexistir. Así ha ocurrido en algunos sistemas comparados que han introducido la valoración de la prueba en concreto, como en Alemania y Francia, donde la declaración de las partes puede producirse de diversas maneras, incluyendo la ordenada por el juez, la solicitada por la contraparte o la ofrecida voluntariamente por la misma parte, coexistiendo dos o más de ellas al mismo tiempo.

En el contexto de un sistema de valoración en concreto, la continuidad de la regla de prueba que permite obligar a una parte a declarar forzadamente no se explica porque esa misma parte no pueda hacerlo voluntariamente. Más bien, la continuidad de la declaración forzada se explica porque en estos procedimientos las partes no tienen derecho a guardar silencio. Así, mientras en el proceso penal el imputado sí tiene derecho a guardar silencio y por ello el órgano estatal que 
demanda la aplicación de una pena no podría citar al acusado como testigo, en materia Laboral y de Familia ello sí podría ocurrir: el demandante puede citar al demandado y viceversa, estando obligado a concurrir, justamente porque no tiene derecho a guardar silencio. Y no sólo estará obligado a concurrir, sino que estará obligado a contestar a las preguntas cuando concurra, porque no tiene derecho a guardar silencio. Por ello, si incumple su obligación de contestar, se le podrán aplicar sanciones: "Si la parte (...) se negase a declarar o diese respuestas evasivas, el juez podrá considerar reconocidos como ciertos los hechos contenidos en las afirmaciones de la parte que solicitó la declaración" ${ }^{82}$ y "Si el Ilamado a confesar (...) se negase a declarar o diere respuestas evasivas, podrán presumirse efectivas, en relación a los hechos objeto de prueba, las alegaciones de la parte contraria en la demanda o contestación, según corresponda" ${ }^{\prime \prime 3}$.

4. "Los jueces sí pueden escuchar a las partes, pero deben hacerlo a través de sus abogados y de lo que ellas mismas sostengan en sus escritos de demanda o contestación":

Los abogados no son medios de prueba. Ellos son asesores y representantes de las partes en el juicio. No han percibido por sus sentidos hechos pertinentes del caso. Lo que digan en el juicio respecto de los hechos, en representación de las partes, deben probarlo a través de otros medios. Lo que digan concluyendo sobre la prueba u otras cuestiones legales ocurridas durante el juicio tampoco constituyen medios de prueba, sino que pura argumentación o razonamiento que pretende persuadir al tribunal sobre algún punto legal. Las partes como medio de prueba, por lo tanto, no pueden ser suplidas por lo que diga su abogado. Cumplen funciones distintas con consecuencias diversas.

Lo mismo ocurre con lo que digan las partes en sus escritos de demanda y contestación. El juez no puede dar por acreditado un hecho controvertido porque creyó lo dicho en la demanda utilizando la misma demanda como fundamento. Esto ni siquiera ocurría en el sistema escrito. Las afirmaciones fácticas controvertidas realizadas en la demanda o contestación deben ser probadas posteriormente en la audiencia de juicio porque estos escritos tampoco son medios de prueba. La función de la demanda y la contestación es otra: fijar el objeto del juicio, enmarcar la disputa, determinar cuáles son los hechos controvertidos, aclarar qué es lo que las partes piden resolver al tribunal. Por lo tanto, para utilizar la información que las partes tienen con el objeto de lograr la convicción del tribunal, es necesario que ellas declaren de acuerdo a las reglas de la prueba: presentándose personalmente al tribunal y contestando a las preguntas que se les haga frente al juez. Permitir que las partes declaren

${ }^{82}$ Artículo 52 de la Ley № 19.968 de Tribunales de Familia.

${ }^{83}$ Artículo 454 Nº3 del Código del Trabajo. 
por escrito en su demanda o contestación violaría las reglas más básicas de la prueba emanadas de la inmediación. Por lo tanto, la demanda y la contestación tampoco suplen la declaración voluntaria de las partes con valor probatorio y el argumento debe ser desechado.

\section{CÓMO OPERARÍA LA DECLARACIÓN VOLUNTARIA DE LA PARTE EN LA PRÁCTICA}

Si bien la ley, tanto en el procedimiento de Familia como en el Laboral, dispone que cualquier fuente de información pertinente puede ser usada como medio de prueba en el juicio, también dispone que éstos deben producirse de conformidad a la ley. Por ello, para saber cómo ella debe rendirse, es necesario primero definir de qué tipo de medio de prueba se trata.

Al respecto hay dos alternativas. La primera es considerar que la declaración voluntaria de la parte es una prueba testimonial más y, por ello, su declaración se produciría en el juicio de acuerdo a las reglas de la prueba testimonial, sometiendo a la parte que declara al examen directo de su abogado, para luego someterse al contraexamen de la contraria y a las preguntas del tribunal. Esta alternativa tiene su fundamento en el cambio de la definición de "testigo" en los sistemas de valoración en concreto. Un testigo, como ya se señaló, no es definido en este tipo de sistemas como un "tercero ajeno e imparcial", justamente porque esta definición, propia del sistema escrito, sólo tenía un sentido instrumental: inhabilitar como testigos a todos aquellos que tuviesen un interés en el resultado del juicio. Como en los sistemas de valoración en concreto no se exige para ser testigo que la persona que declara sea desinteresada, esa definición instrumental carece ahora de todo sentido y debe ser desechada. Para ser testigo en un sistema de libre valoración, de acuerdo a las reglas de la prueba, sólo es necesario que el declarante haya percibido hechos pertinentes para la causa a través de sus sentidos. Esto es lo que diferencia a un testigo de un perito. Mientras el perito va al juicio a emitir opiniones expertas respecto de hechos que no presenció, un testigo va a relatar hechos que presenció directamente y sus opiniones son, por regla general, impertinentes.

Una segunda alternativa es considerar que la declaración voluntaria de la parte no es una prueba testimonial más, sino que una prueba distinta que no está regulada expresamente en la ley. En este caso, de acuerdo a lo señalado por la misma ley, la declaración debiera producirse en el juicio ajustándola en lo posible al medio de prueba más análogo. ¿Cuál es el medio de prueba más análogo? La declaración voluntaria de la parte es prestada por una persona a través de un relato, lo que descarta como medio de prueba análogo a los documentos y a todo otro medio de prueba material, como una filmación, porque no entregan la información que contienen a través de una narración autónoma que pueda ser sometida a un contraexamen. También descarta como medio de 
prueba análogo a la prueba pericial. Si bien en esta última declara una persona que puede ser sometida al contraexamen, su declaración no está constituida por un relato de hechos percibidos directamente a través de sus sentidos, sino que por opiniones expertas sobre hechos que no presenció en su origen. La prueba testimonial, en cambio, es la más análoga: declara una persona, lo hace sobre hechos que ha percibido por sus sentidos y se somete a preguntas. Por último, debe descartarse como medio de prueba más análogo a la declaración forzada de la parte porque en ella el declarante sólo responde a las preguntas de la contraparte (contraexamen), mientras que en la declaración voluntaria además se produce un relato de la misma parte, en el que ella expone al tribunal su versión de los hechos, desde su propio punto de vista, lo que se logra a través de su examen directo, el que no existe en la declaración forzada, y que constituye la razón central por la cual la parte decide declarar voluntariamente. Faltando este elemento esencial en la declaración forzada, no puede ser análoga a la declaración voluntaria.

Por todo lo anterior, sea que se entienda que la declaración voluntaria de la parte es derechamente una prueba testimonial o que se entienda que no es una prueba testimonial propiamente tal, sino que una de aquellas no reguladas expresamente en la ley, el estatuto aplicable en ambos casos, por regla general, será el de la prueba testimonial. Así, la declaración de la parte debe realizarse personalmente, sin posibilidad de sustituir su declaración por otra escrita que la contenga. Debe declarar contestando a las preguntas que primero le haga su abogado y luego a las que haga la contraria, además de las que requiera finalmente el tribunal, al igual que con todo testigo.

¿Cómo debe producirse la declaración voluntaria cuando la piden ambas partes o cuando ambas partes piden la declaración forzada de la otra o una mezcla de todas ellas? La manera de rendir la prueba dependerá de cuál deba producirse primero, es decir, de quien tenga la carga de la prueba. A continuación se presentará una propuesta para resolver las dudas que puedan surgir a partir de la rendición de la declaración voluntaria en estas distintas hipótesis.

a. Si el que tiene la carga de la prueba ha ofrecido su propia declaración voluntaria y, al mismo tiempo, la que no tiene la carga de la prueba ha solicitado su declaración forzada:

Al tener la carga de la prueba, la parte que ha ofrecido su declaración voluntaria comenzará presentando toda su prueba. Por ello, su declaración voluntaria (que forma parte de los medios de prueba para probar su caso) se rendirá antes que su declaración forzada (que forma parte del caso de la contraria).

Al rendir su declaración voluntaria, la parte declarará al tenor de las preguntas que le formule su propio abogado (examen directo). A través de estas preguntas ella irá contando su versión de los hechos. Inmediatamente después, 
la contraparte tendrá la oportunidad, al igual que con todos los testigos de la contraria, de hacerle preguntas (contraexamen).

Las preguntas del contraexamen en el contexto de la declaración voluntaria serían las mismas que la contraparte podría hacerle en la posterior declaración forzada. El contraexamen en la declaración voluntaria es, entonces, un equivalente funcional de la declaración forzada.

Debido a lo anterior, si al presentar sus medios de prueba, la parte con la carga de la prueba rinde efectivamente su declaración voluntaria, con su respectivo examen directo y contraexamen, la declaración forzada pendiente solicitada por la contraria sería, por regla general, sobreabundante, puramente dilatoria, pues materialmente ya se realizó al efectuar el contraexamen. Excepcionalmente podría permitirse la realización de la declaración forzada si con ella se pretende preguntar respecto de información que fue presentada en el juicio después del contraexamen de la parte. En este caso se trataría de información nueva que no ha sido contrastada anteriormente y, por lo mismo, no sería necesariamente sobreabundante.

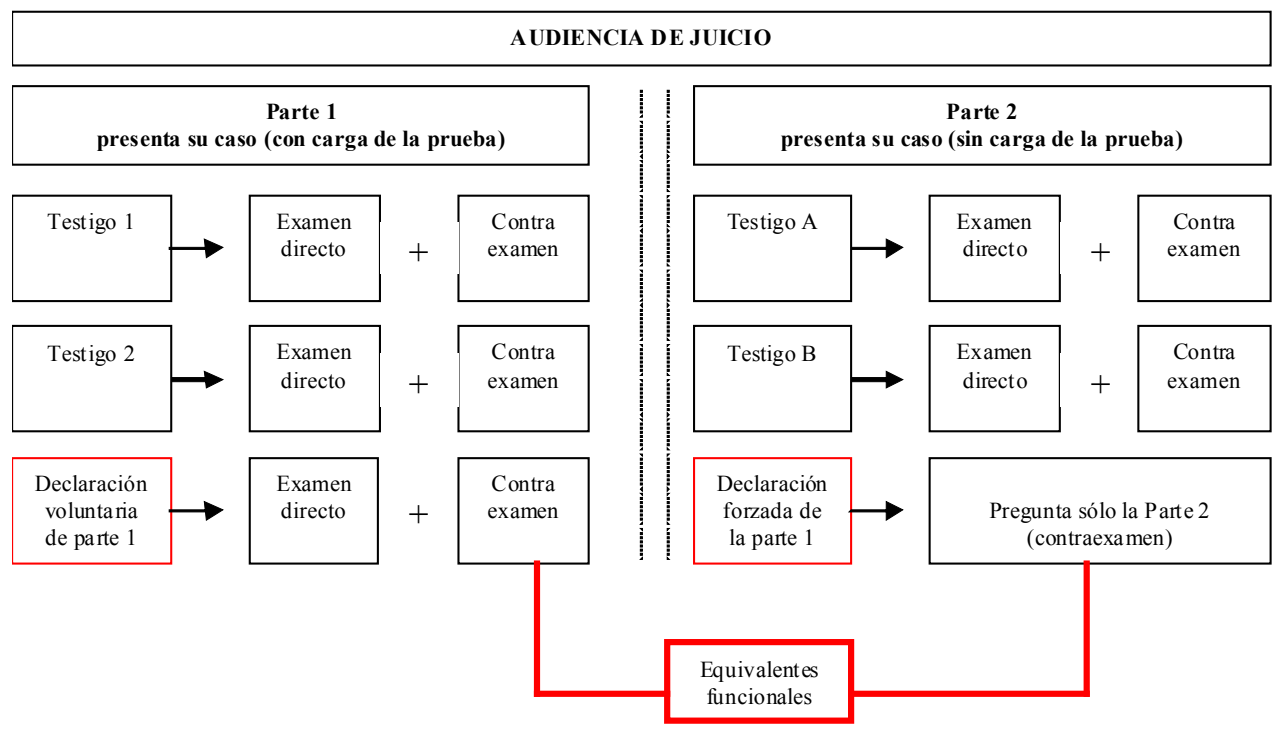

b. Si el que tiene la carga de la prueba ha solicitado la declaración forzada de la contraria y, al mismo tiempo, la contraria ha solicitado su propia declaración voluntaria:

La parte que solicitó la declaración forzada rinde primero su prueba y, por ello, se debiera rendir primero la declaración forzada de la contraria solicitada por ella. Luego, cuando la parte con la carga de la prueba termine de presentar su caso, correspondería que la parte que no tiene la carga de la prueba presente el suyo, dentro del cuál estaría su declaración voluntaria. 
AUDIENCIA DE JUICIO

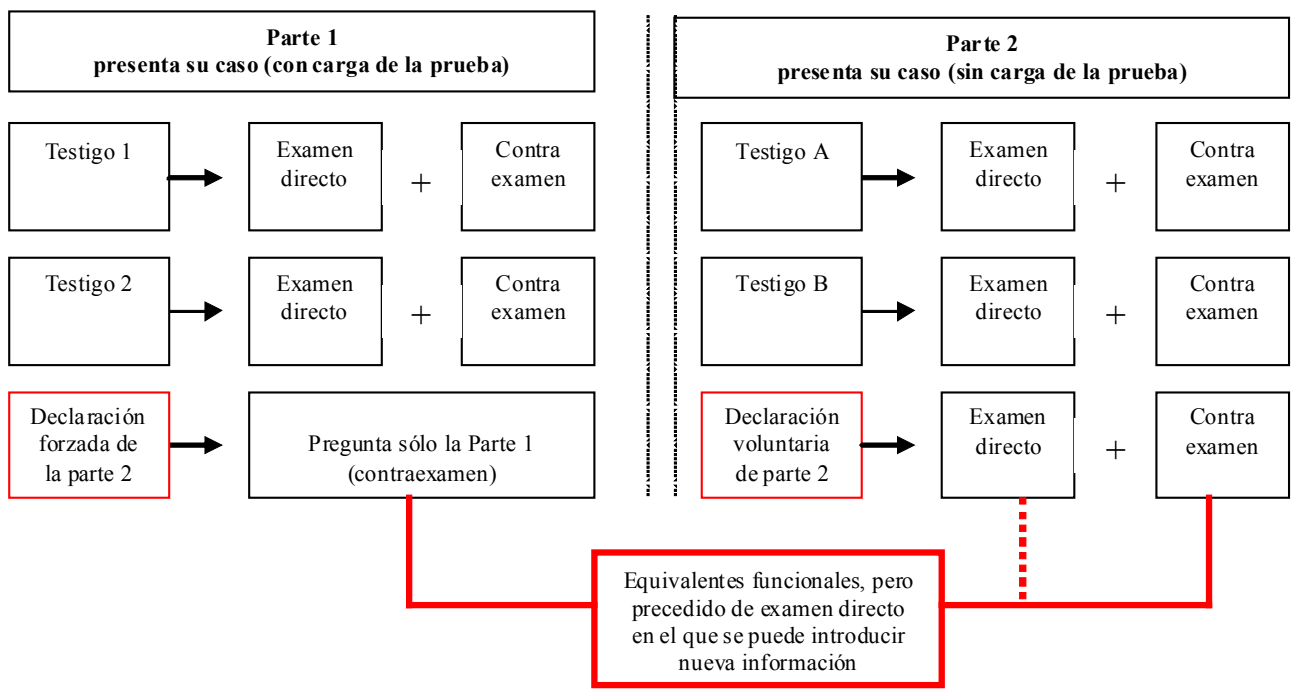

Siguiendo la idea de que la declaración forzada y el contraexamen de la declaración voluntaria son equivalentes funcionales, podría sugerirse la misma solución dada para el caso anterior. Por ello, la parte que solicitó la declaración forzada (que tiene la carga de la prueba) debería esperar la presentación de la prueba de la parte que solicitó su declaración voluntaria (que no tiene la carga de la prueba) y, en el momento en que la rinda, realizar su contraexamen.

Sin embargo, aquí la solución debe ser distinta. La parte que solicitó su declaración voluntaria (que no tiene la carga de la prueba) puede renunciar a rendirla luego de terminada la presentación del caso de la parte que sí tiene la carga de probar. Así podría ocurrir, por ejemplo, cuando la prueba presentada por la parte que tiene la carga de probar no haya logrado superar dicha carga, haciendo innecesario presentar prueba alguna por la parte que no la tiene. Por ello, si la declaración forzada se postergara esperando la realización de la declaración voluntaria y ésta llegara a no producirse, se dejaría a la parte con la carga de la prueba sin la posibilidad de presentar una prueba a la que tenía derecho.

Es por esto que en este caso debe recibirse la declaración forzada cuando la parte que la pidió (que tiene la carga de la prueba) presente su caso. En ese momento, sólo la parte que solicitó la prueba podrá hacer preguntas, es decir, habrá sólo un contraexamen. Si la parte citada a declarar quiere después, al presentar su propio caso, dar su versión de los hechos contestando a las preguntas de su abogado (examen directo), podrá hacerlo al prestar su declaración voluntaria. En este momento, parece también razonable permitir a la contraparte 
realizar un contraexamen nuevamente, aunque sea un equivalente funcional de la declaración forzada que ya se produjo, porque la parte que declara voluntariamente puede introducir en su examen directo nueva información respecto de la cual no hubo posibilidad de contraexaminar cuando se rindió la declaración forzada.

c. Si el que tiene la carga de la prueba ha ofrecido su propia declaración voluntaria y además ha solicitado la declaración forzada de la contraria:

Esta hipótesis no presenta mayor dificultad. La declaración voluntaria de la parte que tiene la carga de la prueba se rendirá según lo ya señalado anteriormente: al presentar su caso entregará su versión de los hechos a través de su examen directo, para luego someterse a las preguntas de la contraparte en el contraexamen, igual que todos los testigos.

A su turno, en la misma presentación de su caso, al producir la declaración forzada de la parte contraria, ésta deberá contestar sólo a las preguntas que le realice la parte con la carga de la prueba.

La misma dinámica se produciría si, a la inversa, fuera la parte que no tiene la carga de la prueba la que solicitó su declaración voluntaria y la declaración forzada de la contraparte.

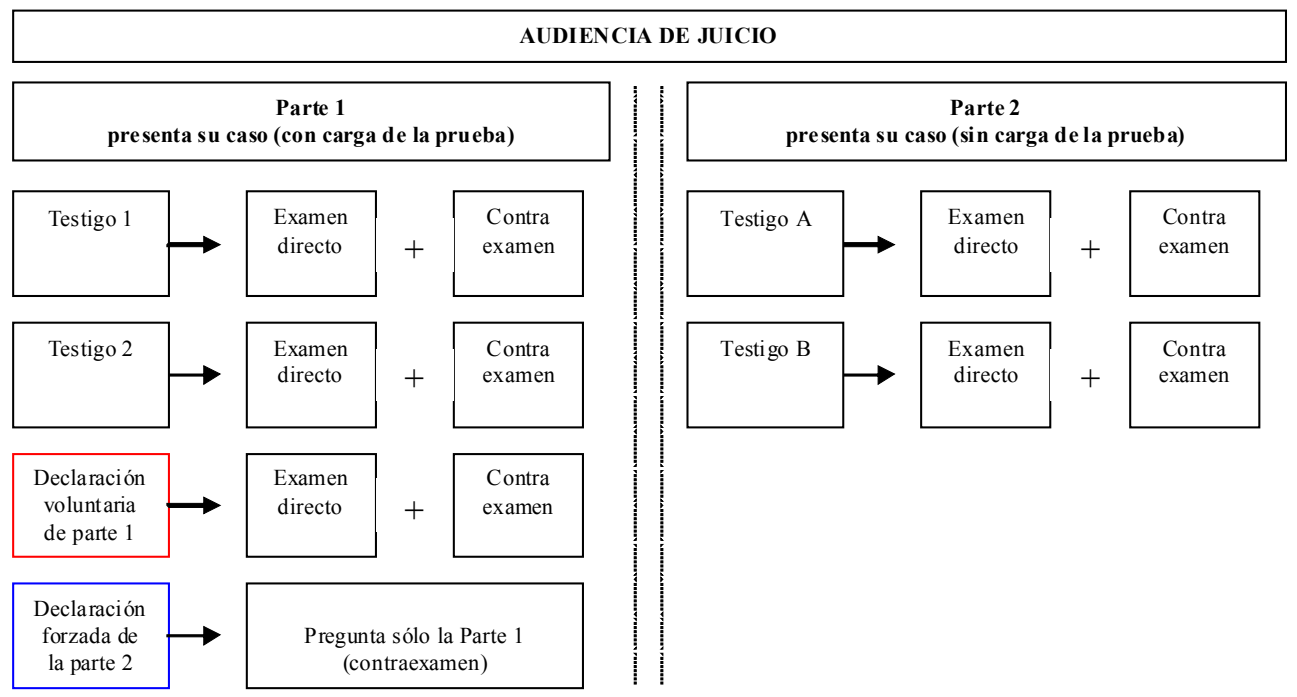

d. Si ambas partes han ofrecido su declaración voluntaria o si ambas partes han solicitado la declaración forzada de la contraria:

Este caso tampoco presenta mayor dificultad. Si ambas partes han solicitado prestar declaración voluntaria, cada una la prestará al presentar su respectivo caso. En el momento en que cada declaración voluntaria sea rendida, la parte 
que declara deberá primero someterse al examen directo y luego al contraexamen realizado por la contraria.

Lo mismo puede decirse si ambas partes han solicitado la declaración forzada de la contraria: cada una deberá producirse en el momento de la presentación del caso de quien la solicitó y la parte citada a declarar forzadamente sólo deberá contestar a las preguntas (contraexamen) realizadas por la parte que la solicitó, sin existir examen directo.

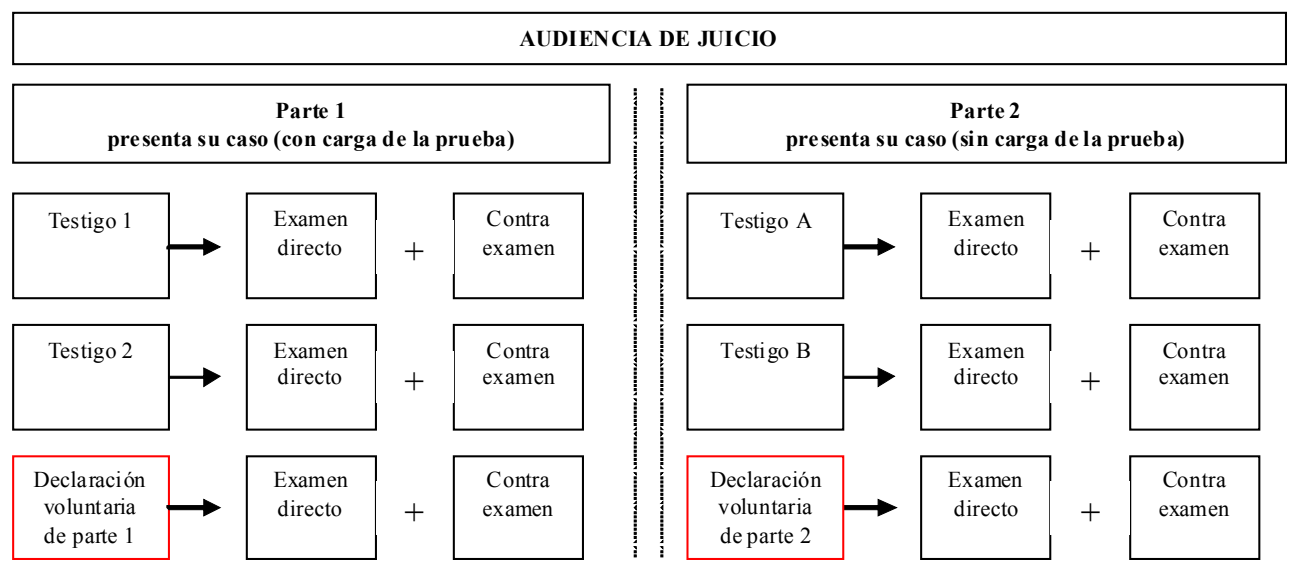

AUDIENCIA DE JUICIO

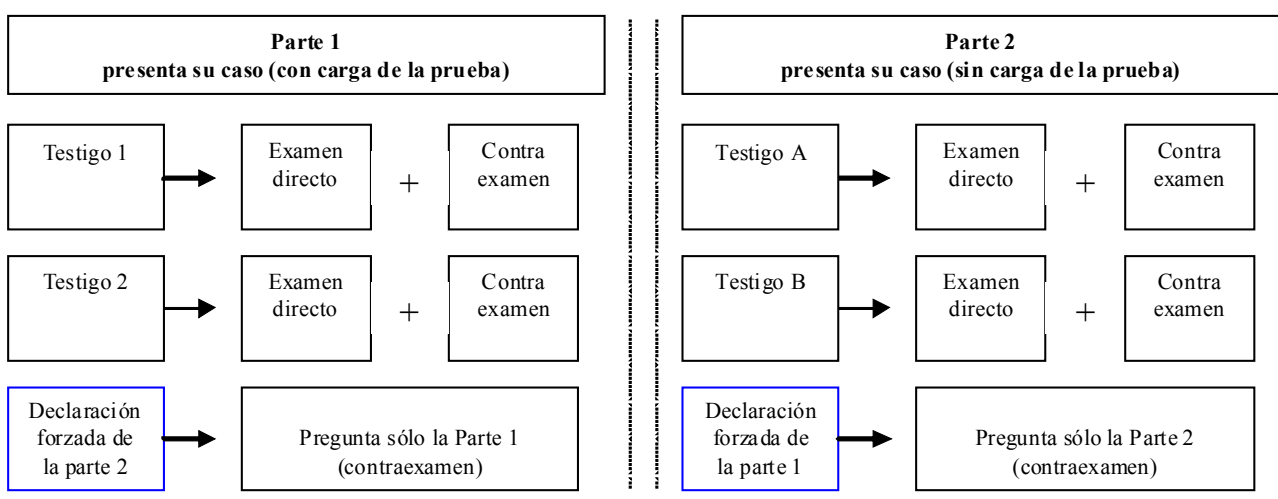

e. Si ambas partes han ofrecido su declaración voluntaria y han solicitado la declaración forzada de la contraria:

La parte que tiene la carga de la prueba rendirá primero la prueba que ha ofrecido. Esto significa que su declaración voluntaria (sujeta a un examen directo y contraexamen) será rendida antes que su declaración forzada solicitada por la contraparte. Por lo mismo, siendo el contraexamen un equivalente funcional de su declaración forzada, esta última resultaría sobreabundante y, por regla general, como ya se ha dicho, no debiera producirse. 
A su vez, la declaración forzada de la contraria solicitada por la parte que tiene la carga de la prueba se rendirá primero que su declaración voluntaria. Cuando declare forzadamente lo hará contestando sólo a las preguntas hechas por la parte con la carga de la prueba, lo que es análogo al contraexamen que se le realizaría en el contexto de su declaración voluntaria. Pero, en este caso, ese contraexamen posterior no sería sobreabundante, y debe estar permitido, porque habría estado precedido de un examen directo en el que la parte puede haber introducido nueva información que no ha sido controlada.

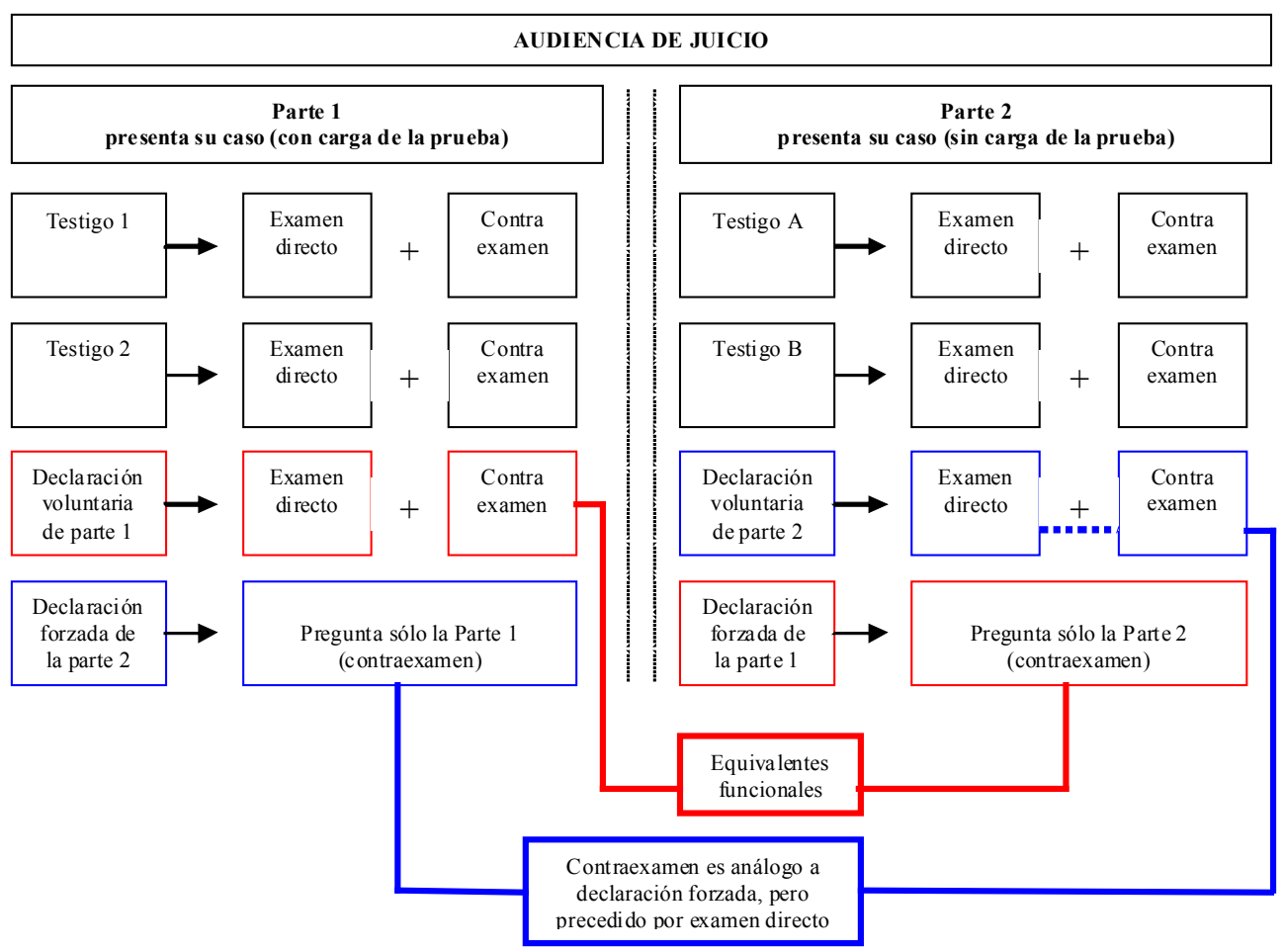

En ambos ordenamientos, las normas sobre testigos exigen que éstos presten juramento o promesa de decir verdad antes de declarar. A su vez, en ambos ordenamientos, no se le exige lo mismo a las partes que son forzadas a declarar por la contraria. ¿Cuál estatuto aplicar a la parte que declara voluntariamente? ¿Debe la parte que declara voluntariamente prestar juramento de decir verdad al igual que los testigos? La analogía correcta aquí parece seguir siendo la misma: debe jurar igual que los testigos. La razón de ello está en la misma justificación que existe para no exigir juramento a la parte que declara forzadamente. Este es el trilema que enfrenta al declarar forzadamente.

En un trilema hay tres opciones y cada una es inaceptable o desfavorable para quien debe tomar la decisión, pero ellas son las únicas tres opciones dis- 
ponibles. En el caso de la declaración forzada de la parte, sus tres opciones son: (1) comparecer al juicio y arriesgarse a contestar una verdad que pueda perjudicarla, con lo que podría traicionar su sentido natural de sobrevivencia; (2) no comparecer, no contestar a las preguntas o dar respuestas evasivas, pero se arriesgaría a que se den por probados los hechos por los que se le pregunta, como explícitamente señala la ley; y (3) mentir para proteger sus intereses, pero se arriesgaría a ser condenada por falso testimonio.

Frente a este trilema, los sistemas legales suelen entregar una vía de escape humanitaria. Algunos garantizan el derecho a guardar silencio, eliminando el peligro de ser sancionado por no comparecer. Otros eliminan la obligación de jurar o prometer decir la verdad, eliminando el peligro de ser condenado por falso testimonio. De esta forma, dentro de las tres opciones disponibles, ya no son todas inaceptables, sino que una de ellas es aceptable para el que la toma.

En materia Laboral y de Familia, el trilema para la parte que declara forzadamente se resuelve liberándola del juramento, por lo que se elimina el riesgo de cometer un delito si no declara la verdad. No tiene en cambio la libertad de no contestar o no concurrir, ya que están establecidas sanciones para estas hipótesis.

Si lo anterior es correcto, ¿cuál debiera ser la solución para la parte que declara voluntariamente? ¿Debe exigírsele juramento? La respuesta es afirmativa porque para ella el trilema no existe: su declaración es voluntaria, por lo que tiene la libertad de optar entre declarar o no hacerlo, lo que, para estos efectos, es análogo al derecho a guardar silencio. Esa es su vía de escape. Es decir, de las tres opciones que tiene disponibles, una de ellas es aceptable. Por ello es que las normas sobre testigos son las que deben ser aplicadas, haciendo jurar a la parte que voluntariamente ha decidido prestar declaración. Si no quiere arriesgarse a decir una verdad desfavorable a sus intereses, entonces puede decidir no declarar.

\section{Algunas palabras finales}

La audiencia de juicio del procedimiento de Familia y del Laboral ha sido diseñada para aplicar el método de razonamiento moderno de valoración de la prueba que permite al juez apreciarla en concreto. Todas sus normas específicas, con mayor o menor éxito y coherencia, intentan realizar este objetivo disponiendo el escenario para lograrlo.

La misma lógica y objetivos del sistema de valoración de la prueba en concreto llevan a concluir que ya no existen las inhabilidades para declarar, ya sea de testigos interesados o de las mismas partes. Coherente con ello, las normas específicas que intentan plasmar la valoración en concreto señalan en la misma dirección: hay un catálogo abierto de medios de prueba; debe 
efectuarse un control de admisibilidad de la prueba sin atender a su credibilidad; a los medios de prueba no regulados explícitamente se les aplican las normas de incorporación del medio más análogo; los litigantes pueden realizar durante el examen de los declarantes preguntas tendentes a producir la información con la cual el juez podrá después valorar la prueba en concreto; el juez puede valorar la declaración de la parte en su beneficio; el juez debe hacerse cargo de toda la prueba rendida en el juicio y; finalmente, se señala explícitamente que debe hacerlo a través del sistema de la sana crítica, es decir, en concreto.

Las razones que en algún momento histórico justificaron la existencia de un sistema de prueba previamente tasada o valorada por el legislador ya no son válidas hoy. Nuestros nuevos sistemas procesales están construidos sobre premisas diferentes. La credibilidad de cualquier medio de prueba no puede prejuzgarse. Por lo mismo, un medio de prueba debe ser recibido antes de concluir algo sobre su valor probatorio. Las inhabilidades para declarar fundadas en razones de credibilidad, por lo tanto, no tienen razón de ser en nuestros nuevos sistemas.

El hecho de que tradicionalmente se haya hecho de otra manera no es un argumento racional ni legalmente suficiente para continuar haciéndolo. Sin embargo, que en el contexto de la implementación de estos nuevos sistemas procesales se constate la supervivencia de esta práctica contraria a la ley debe Ilamar la atención del legislador. En procesos de reforma profundos, en los cuales se instalan nuevas bases, diferentes a las asentadas en la cultura legal existente hasta antes de su llegada, es necesario ser más explícito. La ausencia de una norma que señale positivamente la facultad de las partes para declarar voluntariamente hace más difícil y lento el cambio de prácticas en los operadores del sistema legal.

En este sentido, esta experiencia debe ser tomada en consideración en la discusión del nuevo Código Procesal Civil. El proyecto presentado al Congreso en el año 2009 adolece del mismo vacío en relación a la declaración voluntaria de las partes. Siendo este código norma supletoria de los demás, es también una norma clave para el éxito del funcionamiento de los otros. Con una regulación de las reglas de la prueba correcta, coherente y explícita, este código puede ayudar a llenar los vacíos de los procedimientos aprobados hasta ahora.

Para el futuro quedará un paso todavía más desafiante: la creación de una normativa autónoma, aplicable a todos los procedimientos judiciales, independiente de sus materias sustantivas, que regule la forma en que los hechos deben ser probados en cualquier audiencia de juicio. Esto, que existe en otros ordenamientos, se justifica en que los hechos no tienen una naturaleza jurídica específica. Un hecho no es laboral, civil o familiar en su esencia. Un hecho es un hecho. Otro asunto distinto es que un hecho tenga una determinada con- 
secuencia jurídica de orden laboral, civil o familiar. Por ello es que un mismo hecho puede tener consecuencias jurídicas en más de alguna rama legal a la vez. Por lo tanto, al compartir todos los hechos la misma naturaleza, es lógico que la manera de acreditar su real existencia sea la misma en todo tipo de juicios.

Esto tiene varias ventajas. Entrega una lógica generalmente uniforme para la prueba de los hechos, facilitando a los litigantes y jueces aplicar sus normas, además de su enseñanza en las facultades de derecho. Ayuda a lograr uniformidad en las prácticas de los distintos subsistemas judiciales (familia, laboral, civil, etc.). Elimina inconsistencias, no siempre deseadas por el legislador, entre reglas de la prueba de diferentes procedimientos. Así, por ejemplo, que en materia de familia la ley señale que se debe excluir la prueba "manifiestamente impertinente", mientras en materia laboral la ley sólo señala que la prueba debe ser pertinente, o que en materia de Familia se deba excluir la prueba obtenida ilícitamente impidiendo al juez de juicio conocer su contenido, mientras que en materia laboral ella sólo "carecerá de valor probatorio", abriendo la posibilidad de que sea recibida en el juicio, aunque el juez en definitiva le pueda quitar todo valor, pero sin poder controlar de manera alguna cómo el conocimiento de esta prueba puede haber influido en su convicción interna a pesar de haberle restado valor probatorio formalmente en la sentencia. Otro tanto se puede decir sobre la regulación de la "prueba sobre prueba" o de la "prueba nueva" en materia de familia, cuya ausencia en materia laboral no tiene sustento alguno, o de las normas del procedimiento laboral que determinan de manera rígida el orden en que deben presentarse los distintos medios de prueba en el juicio de acuerdo a su naturaleza: primero la documental, luego la confesional, para seguir con la testimonial y los otros medios de prueba ofrecidos, cuestión que está entregada a la libertad de las partes en materia de familia. Estas diferencias muchas veces sólo se deben a que las respectivas reglas de la prueba fueron debatidas en momentos distintos por personas distintas, pero carecen de una justificación lógica y racional de fondo.

Como se señaló, sin embargo, este es un paso más adelante respecto del cuál hoy en día no ha existido debate. Baste, por ahora, con enfrentar el difícil camino de implementar correctamente las reformas que ya están en marcha.

\section{BibLIOGRAFíA}

AÑez Castillo, María Alejandra, "El sistema de valoración de las pruebas en el proceso laboral venezolano", Revista Gaceta Laboral No 1 Vol. 15, Venezuela, 2009.

Benavente Gorroño, Darío, Derecho procesal civil, juicio ordinario y recursos procesales, $5^{a}$ edición actualizada, Editorial Jurídica, Santiago, Chile, 2004. 
Bentham, Jeremías, Tratado de las pruebas judiciales, Vol. I y II, Traducción de Ossorio Florit, Manuel, Ediciones Jurídicas Europa-América, Buenos Aires, 1959.

Cappelletti, Mauro, El proceso civil en el derecho comparado, Traducción de Sentís Melendo, Santiago, Ediciones Jurídicas Europa-América, Buenos Aires, Argentina, 1973.

El testimonio de la parte en el sistema de la oralidad, Parte Primera y Segunda, Traducción de Banzhaf, Tomás A., Librería Editora Platense, La Plata, Argentina, 2002.

La oralidad y las pruebas en el proceso civil, Traducción de Sentís Melendo, Santiago, Ediciones Jurídicas Europa-América, Buenos Aires, Argentina, 1972.

Carnelutti, Francesco, La prueba civil, Traducción de Alcalá-Zamora y Castillo, Niceto, Ediciones Depalma, Buenos Aires, 2000.

Chiovenda, José, Principios de derecho procesal civil, Tomo II, Traducción de Casais y Santaló, José, Instituto Editorial Reus, Madrid, 1977.

Coloma Correa, Rodrigo, La Prueba en el Nuevo Proceso Penal Oral, Universidad Católica de Temuco, Santiago, 2003.

Couture, Eduardo, Fundamentos del Derecho Procesal Civil, 4ª edición, Editorial B de F, Montevideo, Uruguay, 2007.

, Estudios de Derecho Procesal Civil, Tomo II, $3^{\text {a }}$ edición, LexisNexis, Buenos Aires, 2003.

De la Oliva Santos, Andrés, Casación, oralidad y nuevo proceso civil, Tres conferencias chilenas, Ediciones Jurídicas de Santiago, Santiago, Chile, 2009.

Duce, Mauricio; Marín Verdugo, Felipe; Riego, Cristián, "Reforma a los procesos civiles orales: consideraciones desde el debido proceso y la calidad de la información", en Justicia Civil: Perspectivas para una reforma en América Latina, Centro de Estudios de Justicia de las Américas (CEJA), Santiago, Chile, 2008.

FerRer Beltrán, Jordi, La valoración racional de la prueba, Marcial Pons, Madrid, España, 2007.

GARAPON, Antoine et al., Juzgar en Estados Unidos y en Francia, $1^{\mathrm{a}}$ edición en español, Traducción de Díaz Perilla, Viviana, Legis, Colombia, 2006.

González Castillo, Joel, "La fundamentación de las sentencias y la sana crítica", Revista Chilena de Derecho, Vol. 33 № 1, 2006.

HUNTER Ampuero, Iván, "Poderes del juez civil: algunas consideraciones a propósito del juez de familia", Revista de Derecho № 1 Vol. XX, 2007.

Lazo Cordero, Jaime, "Lógica y sana crítica", Revista Chilena de Derecho № 1, Vol. 36, 2009. 
López González, Jorge A., Teoría General sobre el Principio de Oralidad en el Proceso Civil, Editorial Juricentro, San José, Costa Rica, 2007.

Lorenzo de Membiela, Juan B., "Estudio sincrético del interrogatorio de las partes en la LPL/1995", Sentencias de TSJ y AP y otros Tribunales num. 12/2003 (Comentario), Editorial Aranzadi S.A., Pamplona, 2003.

Medina Cepero, Juan Ramón, "La Valoración Judicial del interrogatorio de las partes en el Proceso Civil", en Repertorio de Jurisprudencia num. 18/2003 (Estudio), Editorial Aranzadi, SA, Pamplona, 2003.

Meneses Pacheco, Claudio, "Fuentes de prueba y medios de prueba en el proceso civil", Revista lus et Praxis № 2 Año 14, 2008.

Morello, Augusto, La Prueba. Tendencias Modernas, $2^{a}$ edición ampliada, Librería Editora Platense, La Plata, Argentina.

PAlomo Vélez, Diego, La oralidad en el proceso civil, El nuevo modelo español, Librotecnia, Santiago, Chile, 2008.

, “¿Proceso civil oral: qué modelo de juez requiere?", Revista de Derecho (Valdivia) n.1 v. 18, 2005.

Pérez-RAgone, Álvaro, "Writ" y "Actio" en el surgimiento y la Configuración del Proceso Civil Inglés Medieval", Revista de Estudios Histórico-Jurídicos XXIX, 2007.

Pérez-Ragone, Álvaro; Palomo Vélez, Diego, "Oralidad y Prueba: Comparación y análisis crítico de las experiencias reformadoras del proceso civil en Alemania y España", Revista de Derecho de la Pontificia Universidad Católica de Valparaíso XXXII, 2009.

Pérez-Ragone, Álvaro; Ortíz Pradillo, Juan Carlos, Código Procesal Civil Alemán, Traducción con un estudio introductorio al proceso civil alemán contemporáneo, Fundación Konrad-Adenauer, 2006, disponible En http://www.kas. de/wf/doc/kas_9523-544-4-30.pdf [visitado el 08/03/2010].

StÜRner, Rolf, "La obtención de información probatoria en el proceso civil", Revista de derecho de la Pontificia Universidad Católica de Valparaíso XXX, 2008.

Taruffo, Michele, La Prueba, Traducción de Manríquez; Laura; Ferrer, Jordi, Editorial Marcial Pons, Madrid, 2008.

, La Prueba de los hechos, Traducción de Ferrer, Jordi Editorial Trotta, Madrid, 2002.

, Sobre las fronteras. Escritos sobre la justicia civil, Traducción de Quintero Beatriz, Editorial Temis, Bogotá, Colombia, 2006.

El proceso civil adversarial en la experiencia americana, Traducción de Beatriz Quintero, Editorial Temis, Bogotá, Colombia, 2006. 
, “¿Verdad negociada?", traducción de Bordalí Salamanca, Andrés, Revista de Derecho, Vol. XXI, № 1, Santiago, Chile, 2008.

, "Investigación judicial y producción de pruebas por las partes", traducción de Juan Andrés Varas Braun, Revista de Derecho (Valdivia) Vol. 15 $N^{\circ} 2,2003$.

, "Poderes probatorios de las partes y del juez en Europa", Revista lus et Praxis № 2 Año 12, 2006. 